Article

\title{
Cyber-Physical Systems for Water Supply Network Management: Basics, Challenges, and Roadmap
}

\author{
Kazeem B. Adedeji ${ }^{1, *}$ and Yskandar Hamam 1,2 \\ 1 Department of Electrical Engineering, Tshwane University of Technology, Pretoria 0001, South Africa; \\ hamama@tut.ac.za \\ 2 ESIEE-Paris, Cité Descartes, BP 99, Noisy-le-Grand, 93162 Paris, France \\ * Correspondence: kezman0474@yahoo.com; Tel.: +27-622-935-332
}

Received: 31 August 2020; Accepted: 10 November 2020; Published: 17 November 2020

check for updates

\begin{abstract}
Water supply systems are dynamic in nature, owing to the effect of climate change and consumer demand uncertainties. The operation of such a system must be managed effectively to meet up with the uncertainties, thus posing a key challenge. Unfortunately, previous information and communication technology (ICT) solutions could not provide the necessary support for applications to deal with the dynamics of the changing physical environment. Nevertheless, tremendous growth in technology offers better possibilities to enhance water supply systems' operations. As a result, development in technology in sensing and instrumentation, communication and networking, computing and control is now jointly integrated with water supply system infrastructures to enhance the water system operations. One such technological paradigm shift is the cyber-physical system (CPS). In this paper, we present the concept of the CPS in the water system context and investigate the CPS applications to water supply system monitoring. Also, the various applications of CPSs and the application domain requirements are outlined. More importantly, research studies on its application to water system monitoring are scrutinized. As such, key challenges sounding the applications in WSSs are identified. We then outline the areas of improvement for further studies.
\end{abstract}

Keywords: communication; control; cyber-physical system; sensing; water quality; water supply systems

\section{Introduction}

In contemporary society, the need for potable water is constantly growing. Unfortunately, the accessibility of water is negatively influenced due to a disruption in the water cycle caused by climate change [1]. This makes water scarcity a key issue around the world. As the water scarcity problem deepens on a global scale, the need for water utilities to adopt a technological paradigm shift for effective use of water resources becomes important. The water utilities aim to supply potable water across the nation through large-scale complex water supply systems (WSSs) or water supply networks. The supply of good drinking water conforms to the objectives of the United Nation's Sustainable Development Goals. However, the achievement of this goal may be hindered by several challenges facing the smooth operation of urban WSSs. Strictly speaking, a key challenge facing the operation of WSS is the frequent water loss level that occurs in the system. The water loss due to leaking pipes occurs in all the system, even though the level varies from one system to the other. This creates a lot of further challenges to water utilities. Further challenges that may arise due to losses in the system include the relatively high cost associated with pumping due to leaks, potential adverse effect of water quality, increased water contamination level, financial losses, and improved maintenance cost to repair leaky pipes [2-6]. When a leak occurs in water supply networks, more energy is needed to sustain the desired level of service [2,3,7]. Unfortunately, the energy cost due to the additional pumping of water is a major issue. For instance, the Water Loss Control Committee of the American Water Works 
Association have suggested that almost 10 billion $\mathrm{kWh}$ of energy produced in the United States is wasted annually on water losses [8]. Therefore, managing the WSSs to address these challenges is a major issue.

To cope with the above challenges, water utilities have made efforts to make WSSs more intelligent by integrating information and communication technologies. As such, tremendous growth in technology provides possibilities and valuable tools to enhance the systems' operations. As a result, development in technology in sensing and instrumentation, communication and networking, and computing and control is now jointly integrated with water supply system infrastructures to enhance the water system operations. Such a system may be regarded as a cyber-physical water system (CPWS). Cyber-physical systems (CPSs) are integrations of networks, computation, and the physical environment, where embedded computing devices ceaselessly sense, monitor, and control the physical environment [9]. CPSs are very closely related to other emerging research topics, such as the Internet of Things (IoT), machine-to-machine (M2M) systems, ubiquitous, fog, and pervasive computing, but with better control capabilities. Sometimes, they are interchangeably used to mean similar concept.

In recent times, CPSs have gained a lot of attention and have enjoyed tremendous growth in various areas of engineering and industrial applications [10-22]. Due to its relevance in engineering applications, research papers on CPSs may be found in the literature [10-22]. The existing body of knowledge has focused on the framework, system design, modelling, and technology implementation of CPSs [19-26]. These papers are very useful, however, they only offer very limited information in the water supply system management perspective. Different from the studies in $[25,26]$, therefore, the objective of this paper was to relay CPS applications in the water system context and identify the limitations, research gaps, and problems to be solved in the application of CPSs to monitoring water system facilities. In addition, we discuss the key features of CPS, present an overview and criticism of the wireless communication technology used in CPSs, investigate the different areas of CPS applications in engineering, and outline the application's requirements for the design and deployment of a CPS in each application. Throughout this paper, emphasis will be on its application to water supply system management. The paper is arranged as follows: Section 2 introduces the architecture of a typical WSS with a brief description of its components. In Section 3, the architecture of CPS, components and functional attributes, and its application domain, including the domain requirements, are presented. Section 4 discusses the review of some selected studies on CPS applications in WSS focusing on water quality and leakage monitoring applications. In Section 5, the challenges of CPSs in those applications and future research directions are presented, while Section 6 concludes the paper.

\section{Water Supply System Architecture}

A conventional WSS is illustrated in Figure 1. It comprises of a water source, water treatment plant and pumping station, transmission mains and distribution networks, and end users. Each of these components is briefly discussed below.

\subsection{Water Source}

This is a raw water collection point. The raw water can be from rivers, lakes, ground waters, underground aquifers, reservoirs, etc. For safe drinking, most of these water sources cannot be consumed directly and must be treated. As such, they are transported via underground pipes to a water treatment station. In a situation where the water source is from a reservoir, the raw water may be transferred directly to the water treatment plant. In some cases, like that of a ground water, the water is pumped by gravity to the treatment plant as shown in Figure 1. 


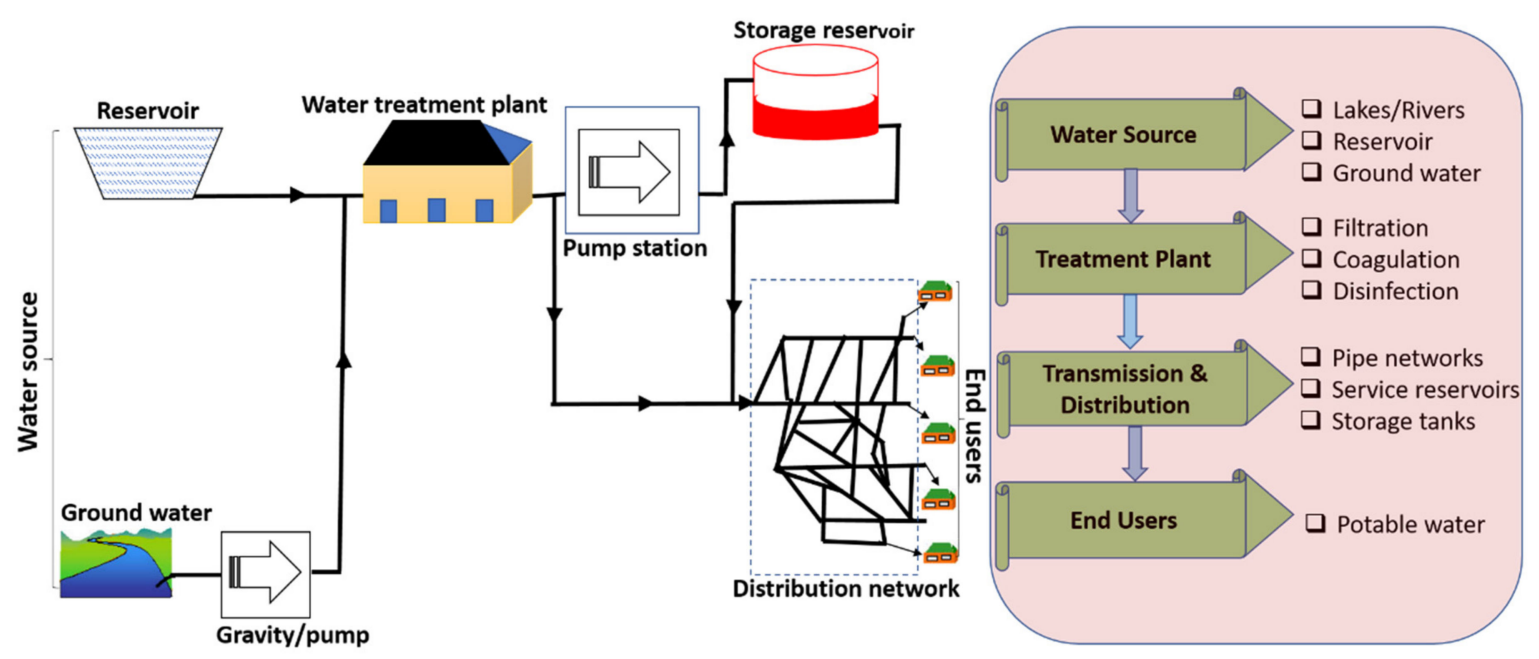

Figure 1. A water supply system architecture.

\subsection{Water Treatment Plant}

This station's primary objective is to safeguard end consumer's health. In this station, the water source is altered through some process to obtain a quality that meets some defined objectives. As such, the raw water is treated and purified in this station. At the treatment plant, conventional methods, such as clarification (filtration, coagulation), disinfection (chlorination), and desalination, take place [27]. Clarification is used to separate suspended water impurities, while the disinfection destroys pathogenic bacteria to avoid waterborne diseases [27]. Usually, desalination procedures are used to deliver to areas where supplies of freshwater are not easily accessible. Freshwater is separated from saltwater by this method. Water quality is efficiently tracked at this station. In some cases, the treated water may be transferred to the distribution system via underground pipes or pumped to a service reservoir for storage.

\subsection{Pumping Station}

The pumping stations are generally located close to the water treatment station and a storage facility. The treated water is directly pumped into the storage facilities, such as reservoirs, tanks etc. In this station, energy is consumed the most. Mamade et al. [28] reported that pumping accounts for $70 \%$ of the energy used during WSSs operation. Similarly, the authority regulating Portuguese Water and Waste Services disclosed that WSS consumes approximately $10 \mathrm{GWh} /$ year for pumping alone, with an estimated cost of around $€ 138$ million [29]. Pumps are one of the major components of a pumping station. Pumps (such as high lift pumps) may be used to pump water directly into transmission mains and distribution systems. To raise the pressure along the pipe, booster pumps can be situated anywhere along the system. Booster pump stations are generally situated remotely in areas with hilly topography where pressure areas are required [30].

\subsection{Water Distribution Networks (WDNs)}

A WDN consists of a network of links interconnected by nodes. The links constitute the pipes, pumps, and valves, while the nodes have the junctions, tanks, and reservoirs. The junctions are points where several pipes are joined with one another. They also serve as water supply or demand points to and from the network. The valves (such as pressure reducing valves, flow control valves, throttle valves, pressure breaker valves, etc.) are utilized to limit the pressure at a point in the network.

The end users are the consumer's tap where potable water is consumed. Besides the impact of climate change which disrupts the water cycle and accessibility [1], water demand at the consuming end also varies with time. These, among other factors such as water leakage, make the management of modern WSSs operations challenging. Nevertheless, WSS operation is generally managed and regulated 
using a set of programmable logic controllers and supervisory control and data acquisition systems. Unfortunately, previous ICT solutions could not provide the necessary support for applications to deal with the dynamics of the changing water demand. Moreover, tremendous growth in technology offers better possibilities to enhance WSSs operations. The incorporation of innovative technologies such as a cyber-physical system into WSSs will, therefore, enhance the operational management of water supply from sustainable perspectives. In the next section of this article, we investigate the architecture of a conventional CPS and its applications to engineering field. In the architecture, reference is made to a water system perspective.

\section{CPS Architecture and Applications}

\subsection{CPS Conceptual Overview}

CPSs are complex next-generation engineering systems integrating embedded computing, control, and communication technologies to monitor a physical environment [25]. Several architectures of a CPS have been reported in the published literature. For example, Dong et al. [23] proposed a bottom-view, four-layer architecture, which comprises of a physical, network, processing, and an application layer. The physical layer encompasses distributed sensors and actuators units for real-time measurements and control. The network layer, which uses wired and wireless communication technologies, offers the basis for data interaction and exchange of information among the units. The processing layer is the data management center, which stores, organizes, and manages the information obtained from the network layer, while the application layer enables the management of resources and real-time monitoring. In Xio-Le et al. [24], a three-layer service-oriented CPS architecture having a physical, network, and service layer was proposed. Similar to the research studies in [21,23,31-33], the physical layer has a module for sensor and actuator nodes, the network layer has the network modules, while the service layer is equipped with the resource and service modules. Considering these studies, a CPS may be perceived as a technology that utilizes the theory of communication, computing, and control to monitor and influence a physical environment. Therefore, as illustrated in Figure 2, a CPS comprises of the physical process, sensing and actuation system, communication networks, and decision system.

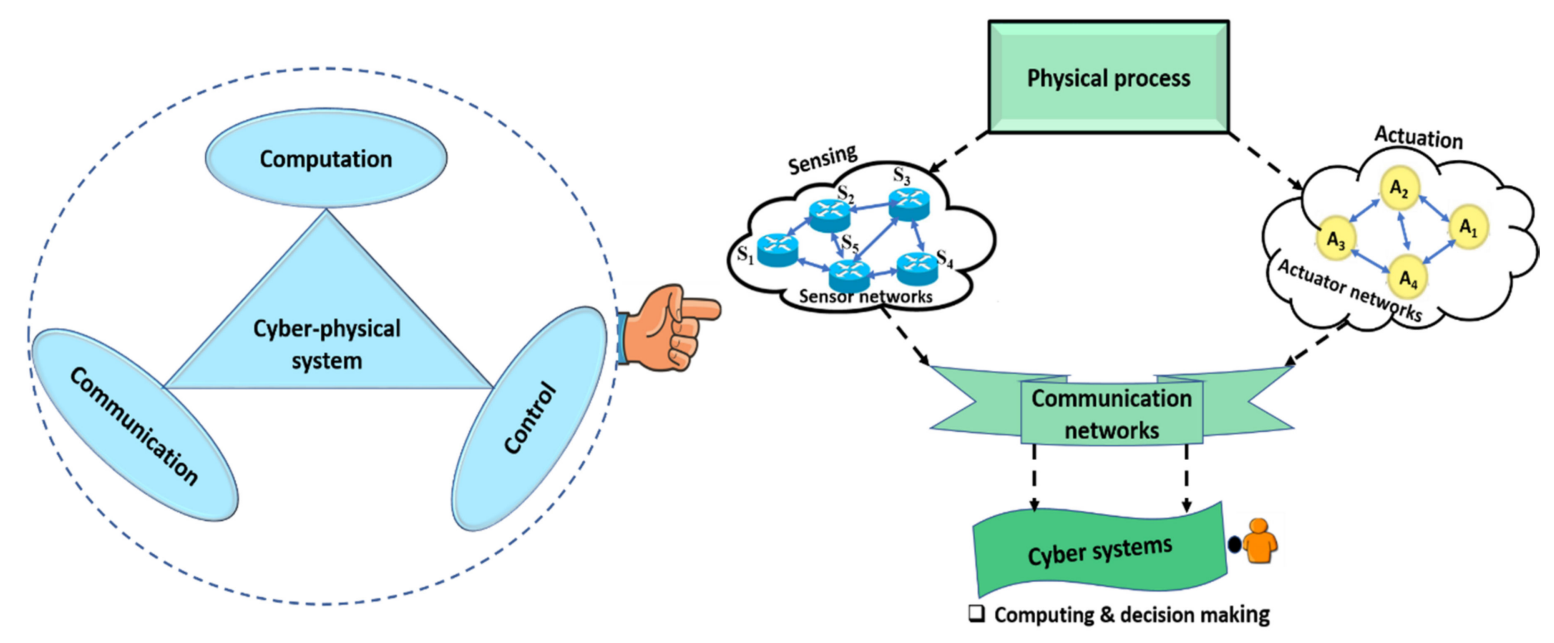

Figure 2. Holistic view of a cyber-physical system (CPS) architecture.

The physical processes are the environment to be monitored or controlled using sensors and actuators. The sensors are usually arranged in a sensor node for seamless communications. The acquired information from the physical process is sent to the cyber systems (where decisions are made) through a communication network. Wireless communication technologies are mostly used in this case. The following sections discuss the components of a typical CPS architecture. 


\subsubsection{The Physical Process}

The physical process refers to the application environments to be monitored. In the water management context, this may include a whole water supply system, such as the one illustrated in Figure 1, or a section/stage in the operation of the WSS, such as monitoring water quality at the water treatment station, monitoring water quality and leakage outflows along the distribution networks, monitoring the energy consumption due to pumping at the pump stations, or water level at the service reservoirs. Also, monitoring the pressure control along the distribution networks is possible. In all of these, monitoring the distribution networks for leaks, pressure control, and water quality is quite challenging because of the complexity and topological structure of water distribution networks, hence, this becomes an utmost priority for most water utilities.

\subsubsection{Sensing and Actuation System}

Just like other emerging technologies, CPSs employ sensors to measure and acquire data from the physical environment. With the latest development in semiconductor technology, intelligent sensors with wireless communication capabilities have been developed. These sensors are low-cost devices with data storage and processing potentials and have been deployed to several applications. In the water domain, they have been utilized for WDN monitoring through leakage and water quality detection $[9,12,15,16,18]$. A selection of multiple sensing elements forming a sensor array having pressure, acoustic, ultrasonic, and temperature sensors may be positioned on pipes for health monitoring. The sensing devices gather data specific to each application and send the data to a distant processing center. In some cases, in-network processing may take place within the sensor networks. The processed data can be utilized for several objectives, such as leak localization. For water supply network management applications, continuous measurement and monitoring of multiple parameters within the pipe is required. For example, in the water quality applications, parameters such as $\mathrm{pH}$, dissolved oxygen, flow rate, turbidity, and conductivity, amongst others, must be measured continuously.

Sensors, as well as actuators, are important elements in a CPS. Sensors are used to acquire data concerning the state of the physical environment. Howbeit, only examining the state of the physical environment is not enough in many applications. It is necessary also to act on the sensed data by performing specific actions. The actuators are therefore used for this purpose. For example, in a water quality application, the sensors gather information regarding the quality of water in a pipe system, while the actuators perform actions such as controlling the opening and closing of the isolation valve to isolate the pipe whose water quality is compromised from the network or to stop the flow of water in such pipe. In a leakage detection application, in the event of leaks, the actuators react by overseeing the control of the pressure reducing valves to reduce pressures at the nodes where the leaky pipe is connected or reduce pressure at the entrance of a district meter area (DMA) where such a pipe is located. This action is to reduce the water loss volume due to the leaking pipes. The actuators are therefore used to trigger various forms of the control command. This step performs the actions determined from the computing phase.

For autonomous monitoring, several sensors and actuators used in tracking the physical environment need to provide continuous measurements for a longer period, as such, they are arranged in a network mode connected by a wireless means. This is regarded as a wireless sensor/actuator network, which is a set of sensors and actuators that are dispersed and interconnected via wireless networks [34]. It is then possible for the CPS to sense, communicate, and execute the appropriate actions to alter the behavior of the physical environment. Conventional sensor and actuator nodes are provided with processing and wireless communication capabilities and a power source. Although actuator nodes possess greater computational and communication capacities and a higher energy budget compared to sensors [34], both are still faced with power constraint issues. Different sensors could produce enormous real-time data that need to be aggregated for further processing. Also, the wireless sensor networks use radio communication technology to relay the acquired data and their design for implementation in water supply network applications, such as pipeline leakage detection, relies on 
the environment in which the pipe is installed [35]. This is fundamental to selecting the type and positioning of the sensors. Sensors may be put inside the pipeline in touch with the water (known as invasive sensors) or as noninvasive sensors, where they are not in contact with the water inside the pipe $[36,37]$. The invasive sensor must, therefore, be robust to cope with the installed environment. It is a known fact that the sensor nodes are powered by battery, therefore, energy conservation is a key challenge that raises concern in the specification of sensor network for real-time pipe health monitoring, as illustrated in Figure 3 [4].

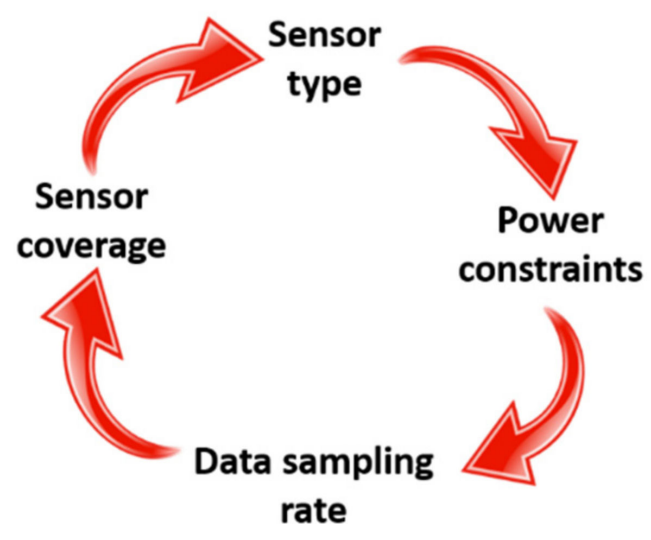

Figure 3. A sensor network design challenge for pipeline health monitoring.

As illustrated in Figure 3, depending on the application domain, the deployment of sensors strongly depends on the sensor type, the power requirements, data sampling rates, and the sensor coverage. For large-scale infrastructure, such as water distribution networks, sensor coverage is a key issue. Also, since continuous measurement of flow rate and pressure along a pipe is required for leakage and water quality analysis, these data need to be sampled continuously, thus, the sensors must offer a high data sampling rate. Also, sensors and the sensor nodes are battery powered, raising concern about the power constraint since the sensors are to run uninterrupted for a very long period. These requirements make the study of CPS sensing systems a hot topic in the research community. Studies on sensor coverage [38-41] and improving the energy efficiency of sensor nodes [42-47] may be found in literature. With the latest progress in sensor technology, mmWave sensors [48] have been developed. These sensors provide multidimensional sensing with precise measurement in both range and velocity and are capable of penetrating certain materials such as plastic and drywall with good resistance to environmental conditions such as rain, fog, dust, and snow [48]. Though the technology is still at its initial stage, it is expected to be a perfect fit for monitoring large-scale critical infrastructure such as water distribution networks.

\subsubsection{Communication Network}

Interactions between different networks (sensors and actuator networks) in a CPS is achieved by wireless communication technology. Just like IoT technology, wireless communication may range from short to long range. The short-range communication technologies may include radio frequency identification (RFID), ultra wideband (UWB), fireless fidelity (Wi-Fi), Bluetooth, near-field communication (NFC), Zigbee, Z-wave, IPv6 over low power wireless personal area networks (6LoWPAN), etc. Amongst others, the long-range communication technologies include GSM/3G/4G, long-range (LoRa), long-range wide area network (LoRaWAN), SigFox, DASH 7, narrow band Internet of Things (NB-IoT), Weightless, etc. Each of these technologies has its own application requirements and challenges. In most CPS applications, short-range communications such as UWB, Bluetooth, Wi-Fi, and ZigBee are mostly used. In this section, we give a short overview and also compare the characteristics of some commonly used wireless communication standards. 
RFID

Radio frequency identification (RFID) utilizes electromagnetic fields (near field or far field) to locate and trace tags connected to an object. It is specified in the standards of the ISO/IEC 18000 series. It operates at different frequencies ranging from low to microwave frequencies with different data rates and communication ranges. At the low frequency (LF) band, it operates at $125 \mathrm{kHz}$ with small data rate and communication range below $1 \mathrm{kbps}$ and $1 \mathrm{~m}$, respectively. At the high frequency (HF) band, RFID operates at $13.56 \mathrm{MHz}$ with data rates close to $25 \mathrm{kbps}$ and a covering distance of around $1.5 \mathrm{~m}$. At ultra-high frequency (UHF), its frequency of operation is in the $860-960 \mathrm{MHz}$ range, covering up to $10 \mathrm{~m}$ with data rates up to about $100 \mathrm{kbps}$, while at the microwave frequency band, RFID operates at $2.45 \mathrm{GHz}$ with good communication range and data rates [49].

\section{UWB}

This is a radio technology utilizing low energy level over a large part of the radio spectrum for short-range communications. The UWB is intended for wireless personal area networks that provide communication distance from a host device to other devices in its nearest vicinity up to a distance of nearly $10 \mathrm{~m} \mathrm{[50].} \mathrm{However,} \mathrm{with} \mathrm{the} \mathrm{short} \mathrm{communication} \mathrm{distance,} \mathrm{the} \mathrm{UWB} \mathrm{can} \mathrm{still} \mathrm{achieve}$ a relatively high data rate [51]. The UWB radio has been deployed for some indoor positioning system applications. Unfortunately, UWB positioning systems are costly because of the high precision clocks needed to evaluate the time gaps between radio signals that arrive at different receivers in the environment [52], so, UWB technology is still very costly.

ZigBee

ZigBee is based on the IEEE 802.15.4 standard for low-cost and low-power consumption with small to medium data rates [53]. It is designed to operate at $2.4 \mathrm{GHz}, 915 \mathrm{MHz}$, and $868 \mathrm{MHz}$ with data rates of around $250 \mathrm{kbps}$ (for the $2.4 \mathrm{GHz}$ ) and 20-40 kbps (for the $868-915 \mathrm{MHz}$ ). As may be noticed in Table 1, ZigBee supports different network topologies, such as star and mesh, to connect hundreds to thousands of devices. As a result of its high throughput and low latency [53], this wireless communication technology is suggested for use in energy-efficient sensor-based applications. Its low communication distance capabilities (10-100 m line of sight (LOS)) limits its usage in large-scale applications, such as water distribution network monitoring.

Table 1. Comparison of the common short-to-long range wireless telecommunication technologies.

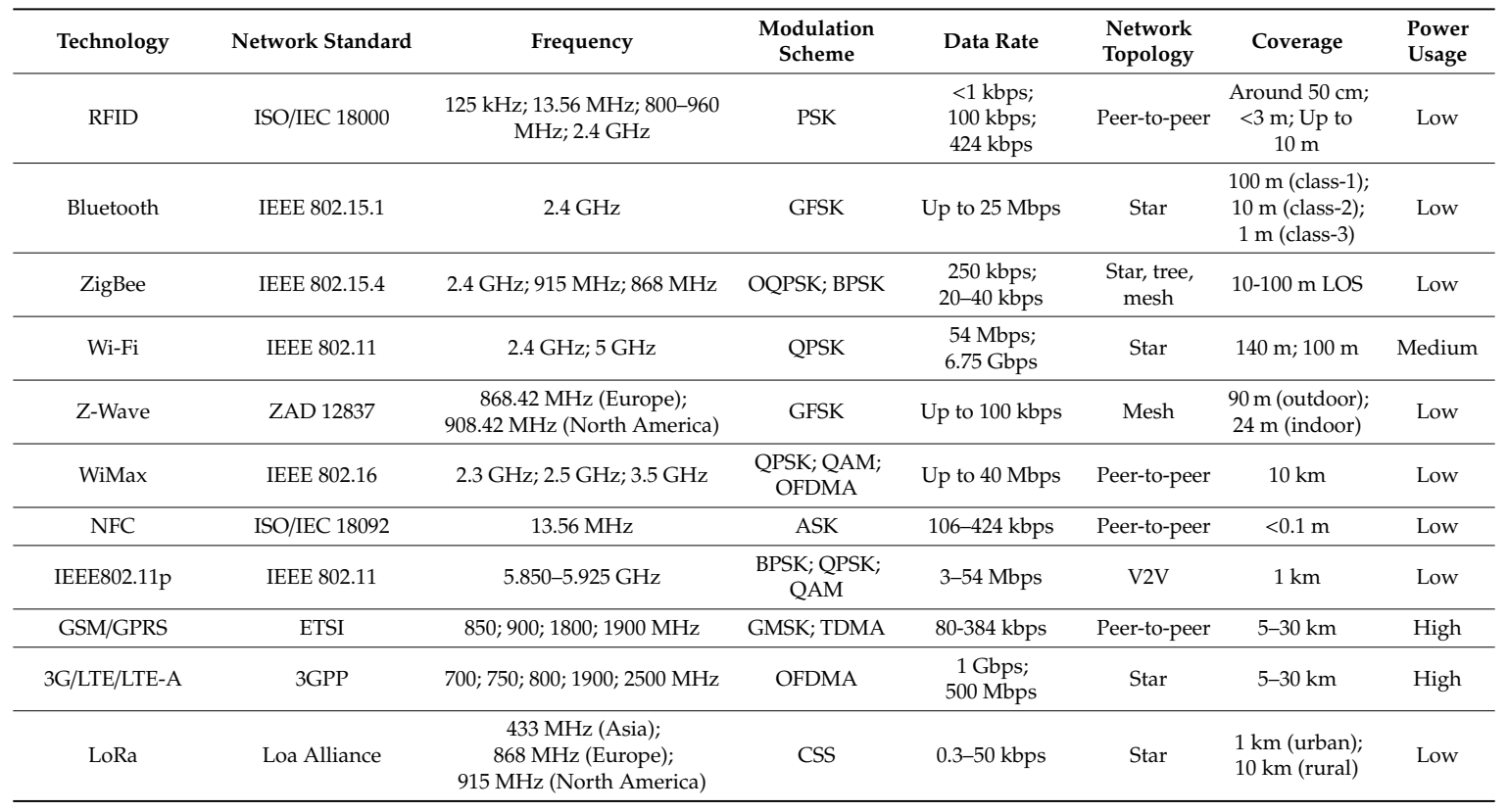


Table 1. Cont.

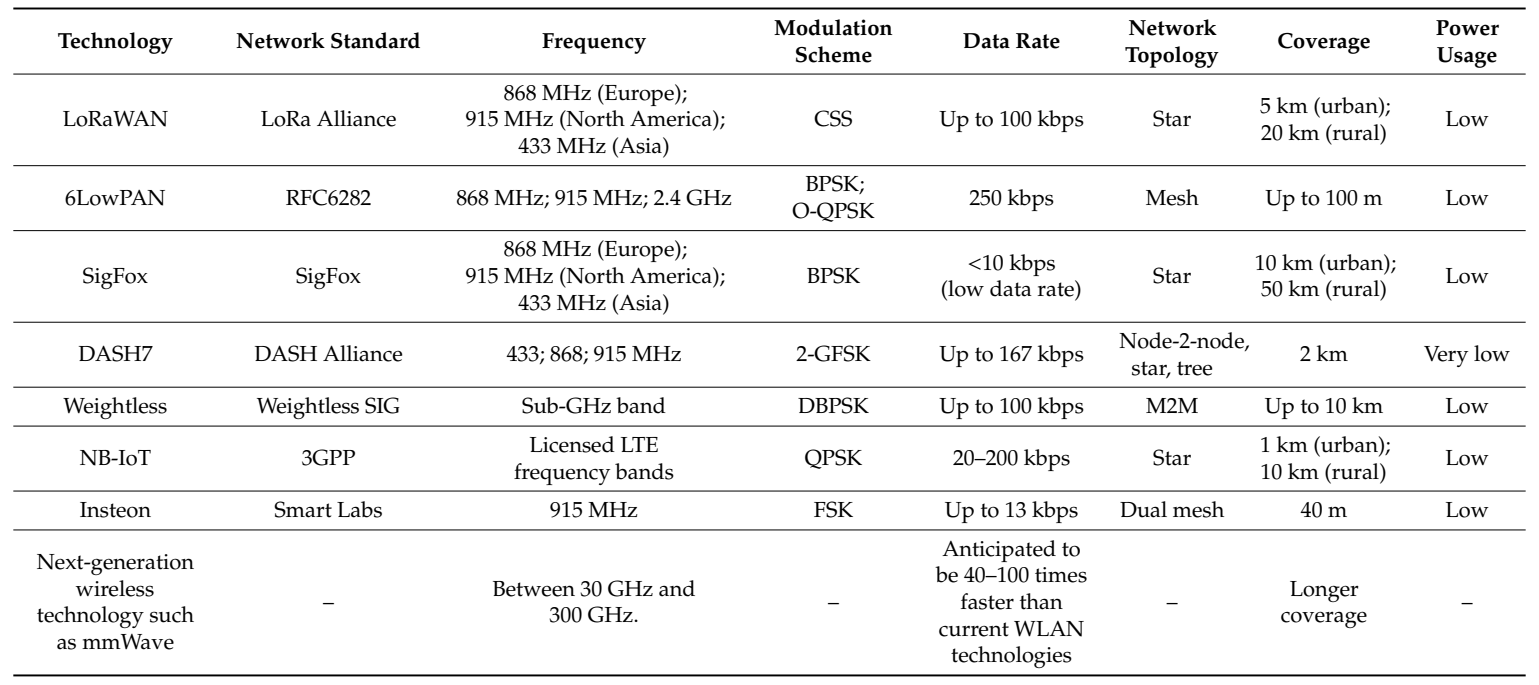

Wi-Fi

Wi-Fi is a trademark of Wi-Fi Alliance, designed based on the IEEE 802.11 standard intended for short-range applications. It utilizes $2.4 \mathrm{GHz}$ UHF and $5 \mathrm{GHz}$ super-high frequency in the industrial, scientific, and medical (ISM) band. It provides higher data rates of $54 \mathrm{Mbps}$ (at $2.4 \mathrm{GHz}$ frequency) and $6.75 \mathrm{Gbps}$ (at $5 \mathrm{GHz}$ frequency) [54]. Wi-Fi uses a quadrature phase shift keying (QPSK) modulation scheme, enabling the signal to carry twice as much data using the same bandwidth. Wi-Fi is low-cost and consumes less power.

Bluetooth

Bluetooth was intended for short-range applications based on the IEEE 802.15.1 standard, supporting both voice and data transmission. It uses $2.4 \mathrm{GHz}$ [53] unlicensed ISM band over limited distances. Distances such as $100 \mathrm{~m}$ (class-1 Bluetooth), $10 \mathrm{~m}$ (class-2), and $1 \mathrm{~m}$ (class-3) are possible. Bluetooth's data rate is smaller than that of $\mathrm{Wi}-\mathrm{Fi}$, but is still characterized with low power, low cost, less complexity, and robustness. Its short communication distance raises concern on its usage for water distribution network monitoring.

NFC

Near field communication (NCF) is a standardized ISO/IEC 18092 wireless communication technology used for short distances, providing bidirectional communication between endpoints [55]. It operates in the $13.56 \mathrm{MHz}$ frequency with a low data rate of around 106 to $424 \mathrm{kbps}$. NCF communication technology uses an amplitude shift keying (ASK) modulation scheme, which offers high bandwidth efficiency. The communication distance is extremely low $(<0.1 \mathrm{~m})$, but the data rate is higher those of ZigBee and Z-wave.

\section{LoWPAN}

The notion behind 6LoWPAN was that low-power devices with small processing capacities should be able to engage in internet tasks. Hence, it enables wireless transmission of data via an Internet protocol possible for smaller devices with relatively low processing characteristics. The 6LoWPAN consumes less power and provides up to $100 \mathrm{~m}$ of communication range.

\section{DASH7}

DASH7 is a wireless communication technology conceived by DASH Alliance to provide a very low power consumption over a long range. It is viewed as an expansion of the active RFID based on 
the ISO/IEC 18000 standard [54,56], with working frequencies of 433, 868, and $915 \mathrm{MHz}$ unlicensed ISM band. By utilizing a two-level Gaussian frequency shift keying (2-GFSK) modulation scheme in the sub-GHz bands [54], DASH7 provides data rates of $167 \mathrm{kbps}$ with communication range around $2 \mathrm{~km}$ [57].

\section{LoRa and LoRaWAN}

LoRa is a promising technology offering low-cost, low-power, and long-range communications. It has a communication range of $1 \mathrm{~km}$ in urban settlements and $10 \mathrm{~km}$ in rural regions [58]. LoRaWAN is based on LoRa and are both standardized by LoRa Alliance. LoRaWAN can be viewed as an upgrade to LoRa with improved data rate and communication distance. LoRa has a low data rate of $0.3-50 \mathrm{kbps}$, while in LoRaWAN, an improved data rate of up to $100 \mathrm{kbps}$ can be achieved. Both wireless communication technologies use a chirp spread spectrum (CSS) modulation, which employs wideband linear frequency modulated chirp pulses to encode information [58,59]. They use an ISM band with a different operating frequency, which differs from one region to the other. For example, in Europe, LoRa and LoRaWAN operate in $868 \mathrm{MHz}$ in Asia and North America, frequencies of around 433 and $915 \mathrm{MHz}$ are reported [58].

\section{NB-IoT}

Narrow-band IoT (NB-IoT) is a new wireless communication technology stipulated in Release 13 of the 3rd Generation Partnership Project [60] to permit a wide variety of cellular devices and services. It utilizes the licensed long-term evolution (LTE) frequency bands and can be utilized in the $2 \mathrm{G} / 3 \mathrm{G} / 4 \mathrm{G}$ spectrum [61]. It employs a QPSK modulation scheme, which allows the signal to carry twice as much information using the same bandwidth. It offers low cost and low power and can cover a distance up to $10 \mathrm{~km}$ in the rural settlements and $1 \mathrm{~km}$ in urban settlements.

\section{SigFox}

SigFox is a low-power wide area network similar to LoRa and LoRaWAN but with an improved communication coverage. It utilizes unlicensed ISM band, which varies between regions, with $868 \mathrm{MHz}$ in Europe, $915 \mathrm{MHz}$ in North America, and $433 \mathrm{MHz}$ in Asia. SigFox wireless communication technologies use a binary phase shift keying (BPSK) modulation in an ultra-narrow band sub-GHz ISM band carrier. Thus, by utilizing the ultra-narrow band, SigFox offers very low power consumption, and low-cost antenna design [58]. In comparison to LoRa and LoRaWAN, SigFox has a very low data rate $(<10 \mathrm{kbps})$, though with very good communication coverage with $10 \mathrm{~km}$ in urban environments and $15 \mathrm{~km}$ in rural areas [58].

A summary and comparison of these wireless communication technologies are presented in Table 1. As shown in Table 1, most of these communication technologies are low-power with varying coverage area and data rates. For instance, Bluetooth and Wi-Fi cover short distances with high data rates. Data rate refers to the amount of data transmitted per unit time. Amongst the low-power wireless communications, SigFox offers long-range capability especially in the rural settings (up to $50 \mathrm{~km}$ ) and it consumes less power. However, its data transmission rate is relatively low. Likewise, LoRaWAN can cover long distances up to $20 \mathrm{~km}$ in rural areas but with a low data rate. Moreover, 3G/LTE and LTE-A cover long distances up to $30 \mathrm{~km}$ and have a relatively high data rate, however, their power usage is very high when compared to some other wireless communication technology. Therefore, for water supply system infrastructure monitoring, long-range communications with a relatively good data rate is a requirement. In CPS, the short-range communications are currently utilized. However, to provide reliable monitoring to water distribution networks (which are large-scale), future CPSs should consider integrating the long-range wireless communication technologies into the system to improve communication coverage. 


\subsubsection{Computing and Intelligent Decision System}

In this stage of CPS, the data acquired are reasoned and further analyzed. Advanced computing methodologies are used to understand, address, and communicate the event that occurs in the physical environment. This allows optimal decision to be made concerning the state of the monitored environment depending on the application, such as safeguarding water sustainability in water supply system applications. The optimal decision making could be carried out through the use of optimization algorithms or decision support systems [62-65]. A decision support system is an interactive software-based system to assist decision makers compile useful information from a combination of raw/processed data to identify and solve problems and to make optimized decisions. In water supply network management applications, the data are the processed or preprocessed sensor data acquired from the physical process. In some cases, data mining techniques have been utilized for data-driven decision making. For example, linear regression, neural networks, and clustering algorithms were deployed for water quality event detection applications [66]. Also, since water supply systems are strongly affected by seasonal variations, Towler et al. [67] proposed probabilistic forecasting methodologies for sequential decision-making during water contamination events detection.

Due to the dynamic nature of water supply systems and consumer demand uncertainties, elsewhere [68-73], advance modelling approaches that cover the complex interaction between water resource, water supply systems, and end user's demand unexpected pattern could improve the decision-making process. One such modelling tool that could be utilized is the agent-based modelling (ABM). ABM is a computational tool that could be used to simulate the actions and mutual interactions of autonomous agents to appraise the cumulative effect on the system considered [69]. From the water supply system management perspective, the agents are the water resource, the water supply system, the water utilities, and the end consumers. An agent is modelled to receive information about their physical environment and select actions to change the environment. Research studies have acknowledged the use of ABM to improve decision-making when an undesirable event occurs in water supply networks. For instance, the ABM approach has been used to assess the effect of contamination on public health for a small town having 5000 residents [70,71]. In [72], an ABM framework was presented for simulating a contamination event in a water distribution network considering social-technical parameters. In this work, the consumers were represented as individual agents. Thus, an agent-based model was integrated with a water distribution system model to capture the dynamics between consumer behavior and that of the water distribution system for predicting the movement of contaminant and public exposure. As the water demand by consumer changed, the demand exerted on the water distribution network was updated, the location of the contaminant within the network was updated, and the quantity of contaminant consumed by each agent was estimated. The framework has been tested through simulating realistic contamination scenarios for a water distribution system. More recently, Huber et al. [73] developed "Aqual.MORE", which is an agent-based system for water demand and supply at a catchment scale. In this system, the agents are classified as water, managers, and users. The water, which is the physical environment to be monitored for contaminant level, represents the discrete quantities of the resource. The users are the consumers that use the resource, while the managers are the water utilities that regulate and manage resource flows to the users. Aqua.MORE [73] simulates the water resources in a demand and supply system, whereby water fluxes and socioeconomic actors are represented by individual agents that mutually interact with each other and cause complex feedback loops. The system performed when demonstrated on water system and could and assist water utility managers during decision making.

\subsection{CPS Functional Attributes}

Owing to the key features of a typical CPS, the future of the technology is promising and may help in optimizing the design and operations of current and future engineering systems and infrastructure. In designing a CPS for specific applications, such as water network management, Lee et al. [19] proposed 
a $5 \mathrm{C}$ functional attribute for the implementation of a CPS. This attribute ranges from connection level (C1) to the configuration level (C5), as may be observed in Figure 4.

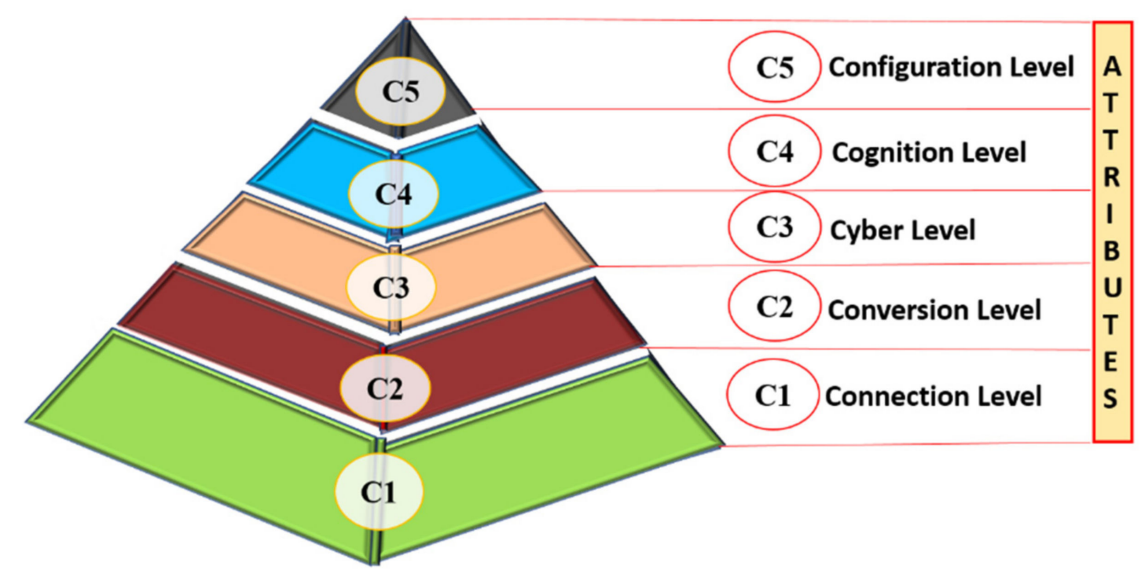

Figure 4. 5C functional attributes for deploying cyber-physical systems.

\subsubsection{Connection Level (C1)}

This level entails providing a seamless connection to the acquired sensor data from the physical environment. To provide a monitoring platform to critical infrastructure such as water supply systems, the data related to this infrastructure must be acquired in a secure way. Thus, in the first level of a CPS, error-free data must be collected. These data are acquired by the installed sensors. The sensors are arranged in sensor nodes to provide seamless connectivity and communications among the sensing elements. Communication protocols, therefore, play a vital role in this level to allow tether-free communication between sensor networks and for data transfer to the central server [10]. Just like the IoT-based technology, low-power communication protocols are requirements for most applications and used for this purpose. Most importantly, sensor selection is crucial at this level depending on the specific applications domain. For example, in the WSS application domain, such as in pipeline leakage detection and localization applications, pressure sensors, flow sensors, accelerometers (to measure vibration on a water pipe surface), ultrasonic sensors, and temperature sensors can be deployed for real-time measurements [4]. Likewise, $\mathrm{pH}$ and water quality sensors may be deployed for water quality monitoring applications. This task is accomplished by deploying the vast categories of sensors at the specific locations along water distribution networks for incessant measurement of water quality and leakage parameters. With CPS, the sensors can be coordinated with respect to their functionalities at this level.

\subsubsection{Conversion Level (C2)}

This level involves converting the acquired data in $\mathrm{C} 1$ to meaningful and useful information needed depending on the applications. This level is equipped with multiple algorithms and data processing methods that handle the conversion processes. In recent years, smart data analytical solutions have been used to obtain data needed for water quality, anomaly, and leakage monitoring in WDNs [74-76]. Elsewhere [77,78], correlation techniques could be performed on the data to extract the information needed for decision making. Extracting information from wireless sensors used in water distribution network monitoring is crucial to analyze the collected data for the specific application. For example, in leakage detection and pipeline health monitoring using acoustic emission (AE) sensors, extracting information from remote $\mathrm{AE}$ sensor signals is required to infer the occurrence of a leak and its location. During leak occurrence, AE sensors positioned on the pipe can trace the AE signal as it travels along the pipe [4]. Unfortunately, signal characteristics and the variations in the environmental parameters surrounding the pipe make AE signal classification challenging [78]. Nonetheless, computational tools, such as support vector machines [74,76], artificial neural networks [79], 
wavelet transform, and independent component analysis [80,81], may be applied for AE signal feature extraction to detect patterns in the dataset and classify the AE signals. These tools are mostly utilized at stage $\mathrm{C} 3$ of the CPS functional attributes.

\subsubsection{Cyber Level (C3)}

This level is the system's central information hub. The information at this level is used to extract additional information about a specific application. For instance, water demand patterns can be further analyzed, and information may be obtained to predict the future pattern of water consumptions. In this analysis, the cyber level algorithms need to be more adaptive and robust [82] to accommodate changed contexts in water demand variations, which may be needed for applications such as water distribution network state estimation, pressure control, and leakage analysis.

\subsubsection{Cognition Level (C4)}

At this level, a task-prioritizing decision is provided to the users. With correct presentations and understanding of the analyzed information from previous steps, the knowledge obtained is used for an optimal decision regarding the state of the monitored water network environment. From the analysis in previous levels, the CPS provides the users with a focus area containing comprehensive information on analysis related to water quality and leakage parameters along a pipe in a water distribution network. Thus, the cognition level aims to apply decision-making and reasoning methods to propose operations such as flushing of affected pipe sections in case of water quality compromise or for pressure control in some selected locations where leaks are frequent (in case of leakage detection applications). This is to enable water supply system sustainability and continuous operations whilst extending the pipe life span. As such, optimization for operation management, maintenance scheduling and planning may be applied to help the user decision at this level [11,62-65].

\subsubsection{Configuration Level (C5)}

The purpose of this level is to enforce the decision made at the cognition level (C4) for monitoring the physical environment. In most cases, the configuration level is usually referred to as feedback from the cyber system to the physical environment [12]. Since the health conditions of the pipes can now be tracked, the CPS does provide early warning failure detection (for leakage or pipe burst) and sends health monitoring information to the operators for active intervention.

\subsection{CPS Applications}

Cyber-physical systems have enjoyed tremendous growth and have frequently been applied in the past, and specifically in recent years, to various engineering and industrial applications. CPSs found common applications in the health sector for the provision of smart healthcare systems, as well as the production and manufacturing sector under the smart factory and manufacturing domain. As may be observed in Figure 5, it has also been applied in the transportation and vehicular domain for provision of autonomous vehicle and smart transportation systems.

Its applications in the infrastructure development sector include the provision of green building, asset management, structural health monitoring (such as bridges), etc. As shown in Figure 5, it has also been applied to monitor large-scale critical infrastructure, such as water and energy grids. More so, its application in the area of robotics and military has also been reported [22]. In each application, the design and effective deployment of CPSs depended on some specific application requirements. In Table 2, we report some common CPS application domain and their specific requirements. 


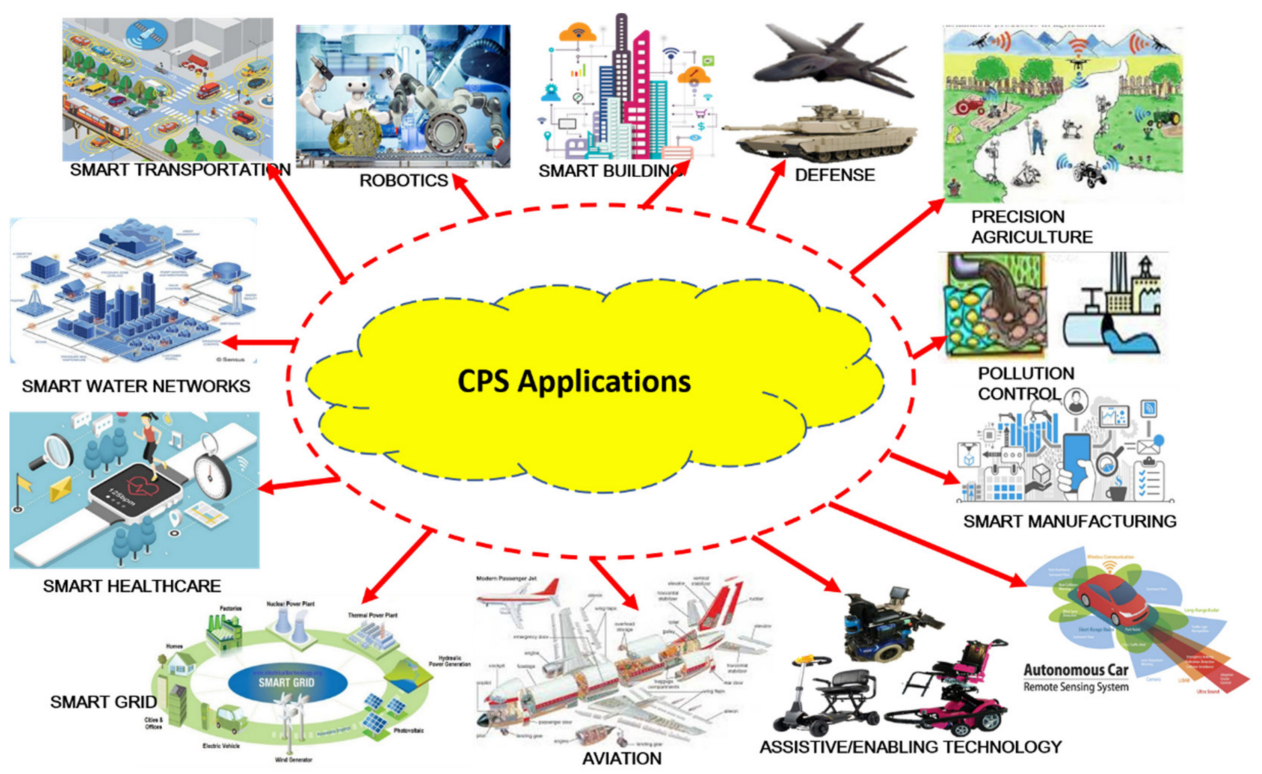

Figure 5. Some applications of cyber-physical systems (CPSs).

Table 2. Some common CPS application domains and requirements.

\begin{tabular}{|c|c|c|c|}
\hline $\mathrm{S} / \mathrm{N}$ & Application Domain & Key Areas of Applications & Requirements \\
\hline 1 & Transportation [13] & $\begin{array}{l}\text { Autonomous vehicle, smart transportation, railroad } \\
\text { systems, vehicular networks and smart highways, } \\
\text { accident signaling, collision avoidance, traffic jam } \\
\text { information, optimal traffic management. }\end{array}$ & $\begin{array}{l}\text { CPSs for the automotive industry demand } \\
\text { high computing power due to complex traffic } \\
\text { control algorithms. Also, robustness, } \\
\text { mobility, and self-adaptation are some } \\
\text { other requirements. }\end{array}$ \\
\hline 2 & Water sector $[12,15,16,18]$ & $\begin{array}{l}\text { Leakage detection and monitoring, leak control, } \\
\text { pressure management, water quality monitoring, } \\
\text { water network monitoring, water flow and pressure } \\
\text { control, water resource management, }\end{array}$ & $\begin{array}{l}\text { Robustness, self-adaptation, flexibility, and } \\
\text { time synchronization. }\end{array}$ \\
\hline 3 & Healthcare sector $[83,84]$ & $\begin{array}{l}\text { Smart healthcare, patient's drug administration, } \\
\text { robotic microsurgery, health management networks, } \\
\text { and epilepsy seizure detection. }\end{array}$ & $\begin{array}{l}\text { Robustness, self-adaptation and flexibility, } \\
\text { high precision sensing, data confidentiality, } \\
\text { mobility, and quality of service. }\end{array}$ \\
\hline 4 & Environment $[14,85]$ & $\begin{array}{l}\text { Wastewater monitoring, industrial waste control and } \\
\text { monitoring, weather monitoring, pollution monitoring, } \\
\text { air quality monitoring. }\end{array}$ & $\begin{array}{l}\text { Robustness and self-adaptation, long } \\
\text { operation without intervention with little } \\
\text { energy consumption. }\end{array}$ \\
\hline 6 & Energy $[10,87,88]$ & $\begin{array}{l}\text { Smart grid, smart energy metering, real-time } \\
\text { cooperative control of protection devices, power } \\
\text { generation and distribution, energy conservation. }\end{array}$ & Robustness, self-adaptation, and flexibility. \\
\hline 7 & Industry $[11,17,19,22,82]$ & $\begin{array}{l}\text { Smart manufacturing, smart production, } \\
\text { robotics, process control. }\end{array}$ & $\begin{array}{l}\text { High flexibility, robustness and security, good } \\
\text { control mechanism, and self-adaptation. }\end{array}$ \\
\hline 8 & Aeronautics/Aviation $[89,90]$ & $\begin{array}{l}\text { Flight test instrumentation, pilot-crew } \\
\text { communications, in-flight tests, flight landing } \\
\text { monitoring, wireless cabin, aviation and } \\
\text { airspace management. }\end{array}$ & $\begin{array}{c}\text { CPSs for aviation require high precision } \\
\text { sensing, robustness, flexibility, precise and } \\
\text { good control mechanism, self-adaptation, and } \\
\text { time synchronization. }\end{array}$ \\
\hline 9 & $\begin{array}{l}\text { Defense/military systems } \\
{[22,91,92]}\end{array}$ & $\begin{array}{l}\text { Firefighter monitoring, soldier supervision, emergency } \\
\text { navigation, target tracking, defense jets, etc. }\end{array}$ & $\begin{array}{l}\text { Robustness, flexibility, self-adaptation } \\
\text { (adaptability), military data integrity } \\
\text { provision, precise control, high precision } \\
\text { sensing, time synchronization, } \\
\text { and good coverage. }\end{array}$ \\
\hline
\end{tabular}

In modern-day engineering applications, robustness, flexibility, and adaptability are major requirements. In deploying a CPS to monitor a dynamically changing physical environment, such as water supply systems, the CPS design must be such that it can adapt to the changing conditions 
and uncertainties of water demand that occur in the system. Besides the demand uncertainties from the consumer side, climate change influences the source water, which then affects the operation of the system. Also, water demand varies with time and seasons, therefore, in the self-adaptation, CPSs must react in a timely manner to the dynamic nature of the water supply system to achieve better performance. In some other applications, changing weather conditions (environmental applications), changes in enemy or target position (defense system), changes in altitude and air turbulence (aviation), and changes in energy demand (energy sector) make adaptability a key requirement in the design and deployment of CPSs in those applications. In the military system for target position location and water system for leak location, time synchronization of the monitoring devices is one of the major requirements. A small-time deviation may cause a large location error [95]. A CPS application in assistive technology must support mobility and passive supervision. In aviation and defense systems, it demands high precision sensing, accurate control, high security, and high-power computing. Defense applications require active intervention to support target mobility with good coverage.

Industrial goods have been faced with several consumer requirements over the years. A CPS in smart manufacturing must, therefore, offer a high degree of flexibility to satisfy the growing and varying demand for goods. In the environmental application domain, a CPS must swiftly act to provide emergency responses in areas where natural or man-made disasters occur [96]. As mentioned earlier, the pattern of water demand is heavily influenced by uncertainties and demand and seasonal variations. As such, a CPS adopted for water quality monitoring or water supply system management must be robust, flexible and adapt to respond rapidly to consumer demand variations or water demand for fire-fighting in the event of a fire disaster. Also, faster responses to detect possible water contaminant and to give awareness of contaminant in the water system even under the demand uncertainties. In these applications, the CPS must operate with minimal energy consumption of the sensing systems for long periods of time without human intervention.

\section{Selected Studies on CPS Water Supply Network Management}

In this section, research papers reporting the application of CPSs in the water domain to monitor water system facilities are reviewed. As illustrated in Figure 6, we categorized the water supply network management (WSNM) application domain as water quality monitoring (WQM), leak detection and monitoring (LDM), pressure control and monitoring (PCM), parameter estimation and monitoring (PEM), state estimation and monitoring (SEM), demand prediction and monitoring (DPM), pipe health monitoring (PHM), pump energy consumption monitoring (PECM), and water resource management (WRM).

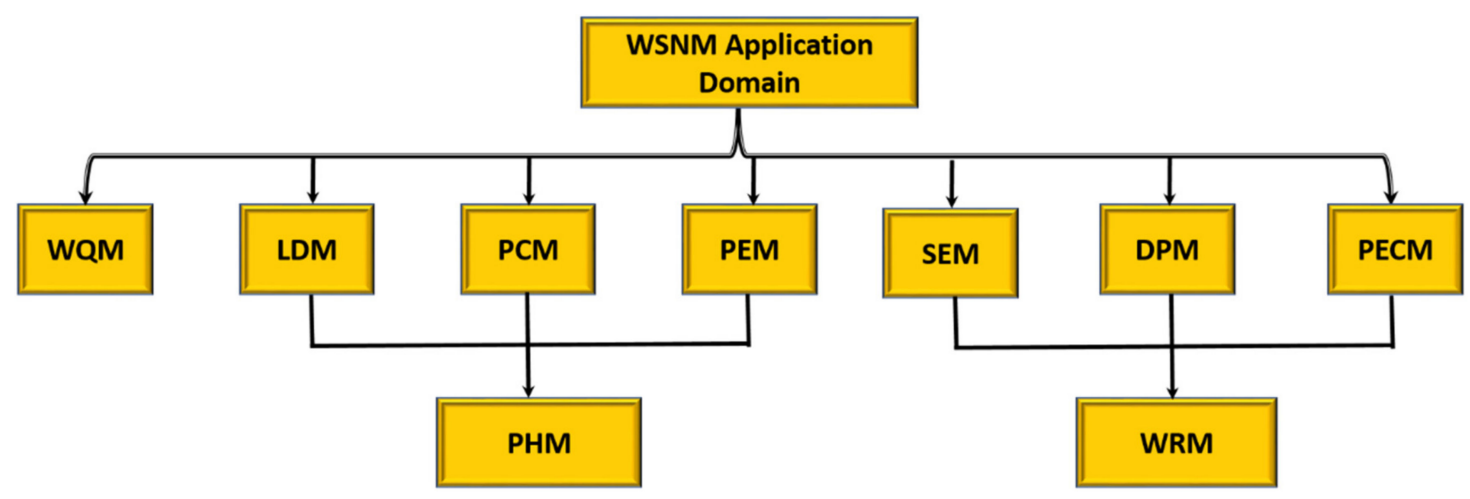

Figure 6. Water supply network management WSNM application domain.

Of these categories, the application of a CPS to WQM and LDM are famous and have been reported in the literature. Thus, the discussion in this section is based on these two applications. It is worthy to note that, in water supply systems, the quality of water can be successfully monitored at the treatment plant and pumping stations, the major problem occurs in the distribution networks due to 
pipe burst and leaks occurrence along the network. Thus, the application of a CPS to water quality and leak monitoring in the distribution networks was our focus. As such, we categorized these discussions under water quality monitoring applications, and leakage detection applications.

\subsection{CPS Water Quality Monitoring Applications}

In the CPS applications to monitor water distribution networks, the type of sensing devices to be deployed for each application depends on the measured parameters. In the water quality and pollutant detection applications, parameters such as $\mathrm{pH}$, temperature, turbidity, dissolved oxygen concentration, and chlorine residual levels, amongst others, are essential. A summary of these parameters and their threshold values is given in Table 3. As may be noticed in Table 3, the World Health Organization [97] provides a $\mathrm{pH}$ range of 6.5 to 7.85 as a standard value to prevent excessive acidic or alkaline water consumption. Also, a temperature of $15^{\circ} \mathrm{C}$ is considered safe for a drinking water system. If these parameters are sensed to exceed the limit, an alarm is initiated and the appropriate agencies or utilities at the monitoring center make optimal decisions.

Table 3. Summary of the water quality parameters for drinking water system.

\begin{tabular}{cccc}
\hline Measured Parameters & Sensor Type & Threshold Value & References \\
\hline Temperature & Temperature sensors & $15^{\circ} \mathrm{C}$ & WHO [97] \\
\hline $\mathrm{pH}$ & $\mathrm{pH}$ sensors & $6.5-7.85$ & WHO [97] \\
\hline Dissolve oxygen concentration & Dissolve oxygen sensors & $5-6 \mathrm{mg} / \mathrm{L}$ & {$[98,99]$} \\
\hline Sodium & - & $200 \mathrm{mg} / \mathrm{L}$ & WHO [97] \\
\hline Fluoride content & - & $4 \mathrm{mg} / \mathrm{L}$ & WHO [97] \\
\hline Residual chlorine & Chlorine residual sensor & $3 \mathrm{mg} / \mathrm{L}$ & WHO [97] \\
\hline Turbidity & Turbidity sensor & $0-5 \mathrm{NTU}$ & WHO [97] \\
\hline Oxygen reduction potential & ORP sensor & $\pm 2000 \mathrm{mV}$ & {$[100]$} \\
\hline Conductivity & Conductivity sensor & $500-1000 \mu \mathrm{S} / \mathrm{cm}$ & WHO [97]
\end{tabular}

In the study conducted by Imen and Chang [12], advanced remote sensing and sensor technologies were utilized to acquire a huge amount of data to capture changes in water quality parameters along a pipe network. The proposed system is also equipped with a cyber-interface, which provides a platform for early warning awareness about water contaminant. While the system is still at its initial stage, the associated cost of implementation is a major concern as the system deploys a huge number of advanced remote sensing technologies for real-time measurements. In Lambrou et al. [101], a low-cost system for real-time monitoring of water quality parameters was developed. The system also uses a sensor array to acquire data related to turbidity, oxidation reduction potential, temperature, $\mathrm{pH}$, electrical conductivity, and flow rate within the pipe. Also, communication of the sensor readings to a processing center is provided via a ZigBee module. The research effort of Sun et al. [9] considered the application of a CPS in both the drinking water system and the drainage system. Different from other studies [12,101], the proposed system integrates a model prediction control for optimizing control with current measurements of the installed sensors and to predict the future behavior of the system. The use of a multisensor array for real-time measurement of water quality parameters in a water distribution network was proposed by Bhardwaj et al. [100]. The sensing framework acquires data related to $\mathrm{pH}$, dissolve oxygen concentration, oxygen reduction potential, conductivity, and temperature. Also, a soft computing framework (using python and fuzzy logic) is integrated into the system for computational modelling and to facilitate decision making. Similar to the studies presented in $[9,12,16]$, the system was able to monitor the water quality parameters in the WDN. However, the accuracy and the operational performance of such a system depends largely on the sensing framework and the robustness of the integrated sensors. 
In an effort to address some of the challenges in those research studies and make the system robust, $[26,102]$ incorporated a water quality hydraulic modelling into the system for contaminant prediction and detection. Wang et al. [26] proposed an architecture of a typical cyber-physical water system utilized for water pollutant detection. The proposed system consists of sensing devices (with water quality sensors) arranged in a sensor network, a hydraulic model, and energy-harvesting platform, as shown in Figure 7 [26].

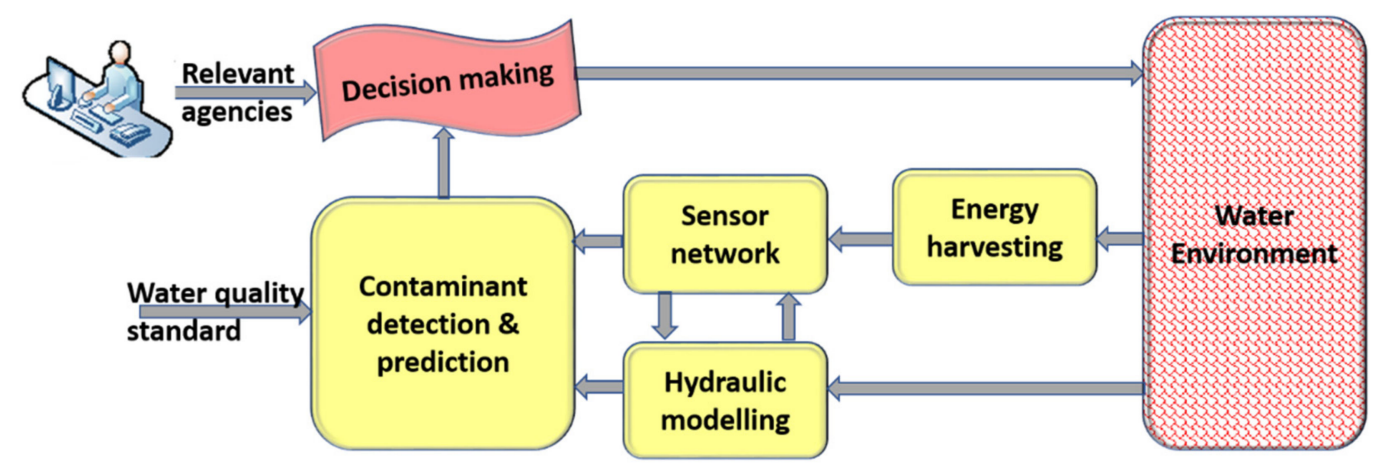

Figure 7. A typical CPS for water quality monitoring.

The water quality sensors provide real-time measurement of the water pollutant from the system. Also, a water quality hydraulic model is blended with the sensor real-time measurements to predict water pollutant occurrence in the water environment. The predicted pollutant and the real-time measurement from the sensors are fed to the decision-making block. This block allows the optimal decision for immediate action to be taken on water contamination before it spreads to the entire system. In most cases, necessary actions include the closing of valves at the particular node where the pipe conveying the contaminated water is attached. The valves installed at the entrance of a DMA of the water distribution network could also be controlled to stop the spread of contaminant. This is an advantage of partitioning a water system in DMAs for the monitoring and reduction of potential impact of contaminants [102,103]. The system is also equipped with an energy harvesting methodology to improve the power consumptions of the sensors. Similarly, Nasir et al. [104] proposed a CPS framework for in-pipe water monitoring. The proposed system, regarded as PipeSense, is made up of six tiers interconnected as indicated in Figure 8 [104].

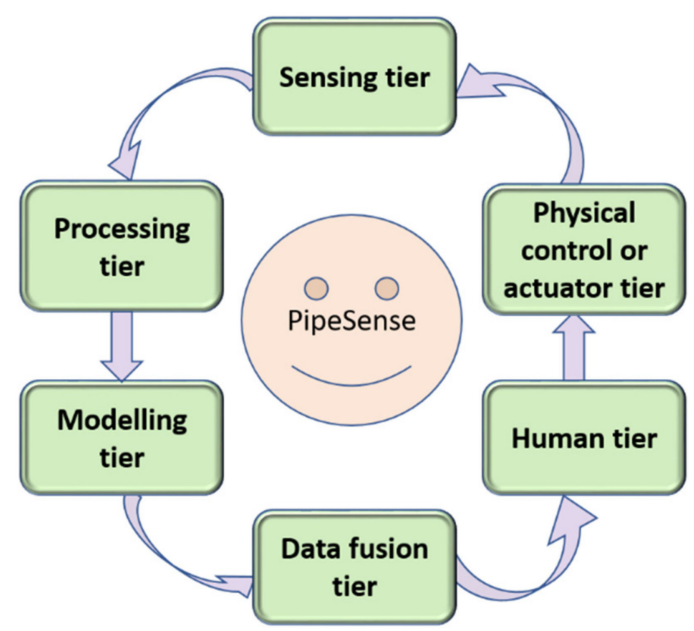

Figure 8. A CPS architecture for in-pipe water monitoring.

In Figure 8, the sensing tier comprises of a flow, pressure, $\mathrm{pH}$, and water quality sensor to gather data for water flow, pipe water pressure, $\mathrm{pH}$, and contaminant level. The measured sensor data are transferred to the processing tier for data analysis and processing. In this tier (the processing tier), 
extensive data extraction is performed in real-time, which is then fed to the modelling tier. The data from the processing tier could also be stored for future reference. In the modelling tier, a water quality hydraulic model is used to estimate the water contaminant level. The output of this tier is sent to the data fusion tier, where the information from the hydraulic model and the processed data are fused. The human tier makes the optimal decision based on the information from the previous tiers. The decision makers at this tier could be sent to an actuator to control the spread of contaminant within the system. A section of the network where the effect of the contaminant is detected could be isolated with the help of the actuators.

In most of the studies presented for water quality monitoring, there is higher uncertainty in using the developed system to give information concerning the source of the contaminant. More importantly, the associated cost of implementation is a major concern as the system deploys a huge number of sensors for real-time measurements.

\subsection{CPS Leak Monitoring Applications}

Nasir and Soong [105] proposed an RFID-based architecture for pipe leak monitoring. The application of the proposed system was demonstrated on a small laboratory test involving simple piping runs, however, the feasibility of the system on a real water distribution system is a major concern. Most water piping runs are installed underground, however, RFID system suffers from poor signal strength in underground environments. Kartakis et al. [106] proposed a test for leak monitoring in water networks using integrated flow and pressure sensors. In Lang et al. [15], a CPS framework for leak localization in multibranch pipelines was proposed. Several sensing devices arranged in a network mode were utilized to acquire data related to the pipe internal pressure, flow rate, and temperature. Also, communication between the sensor network and a base station was provided via Wi-Fi, ZigBee, and 3G communication technologies. Due to the fact that the pipe internal pressure varies and is nonstationary, during data processing, a wavelet packet was employed to decompose and analyze the pressure signal for leak localization. The framework was simulated in MATLAB and Flowmaster software environments with some level of success regarding leak localization. However, a real-time application is a major concern. Elsewhere, several computational tools have been used to analyze the nonstationary pressure wave signals. Zhang et al. [80] proposed a hybrid method employing independent component analysis and the support vector machine for analyzing pressure traces with relatively good accuracy. Also, in [107], an interactive self-organizing data analysis algorithm was utilized for the pressure traces analysis in the pipes. Studies on the use of artificial neural networks (ANN) and fuzzy ANN in this domain may also be found in the literature [108-110] with some level of success. Unfortunately, most of these techniques cannot efficiently handle some variations that occur in real-time pipe environments, such as the state of flow within the pipe (transient operations in most cases), state of the surrounding soil (underground pipe applications), and the leak characteristics (hydraulic nature of leaks discharge). Therefore, their adoption for real-time applications is uncertain. Also, small leaks cannot be analyzed and detected, therefore, it is quite clear that they cannot be used for background leak detection, in which there is a small, continuous discharge running along the water distribution networks.

\section{CPS-WSS Monitoring Application Challenges and Future Directions}

\subsection{Application Challenges}

The increasing number of applications of CPSs in various areas of the water supply system cannot be overemphasized. Despite their promising growth, such systems are faced with several challenges. The list outlined in this section covers some of the challenges faced by CPSs in water supply network management applications, as illustrated in Figure 9. 


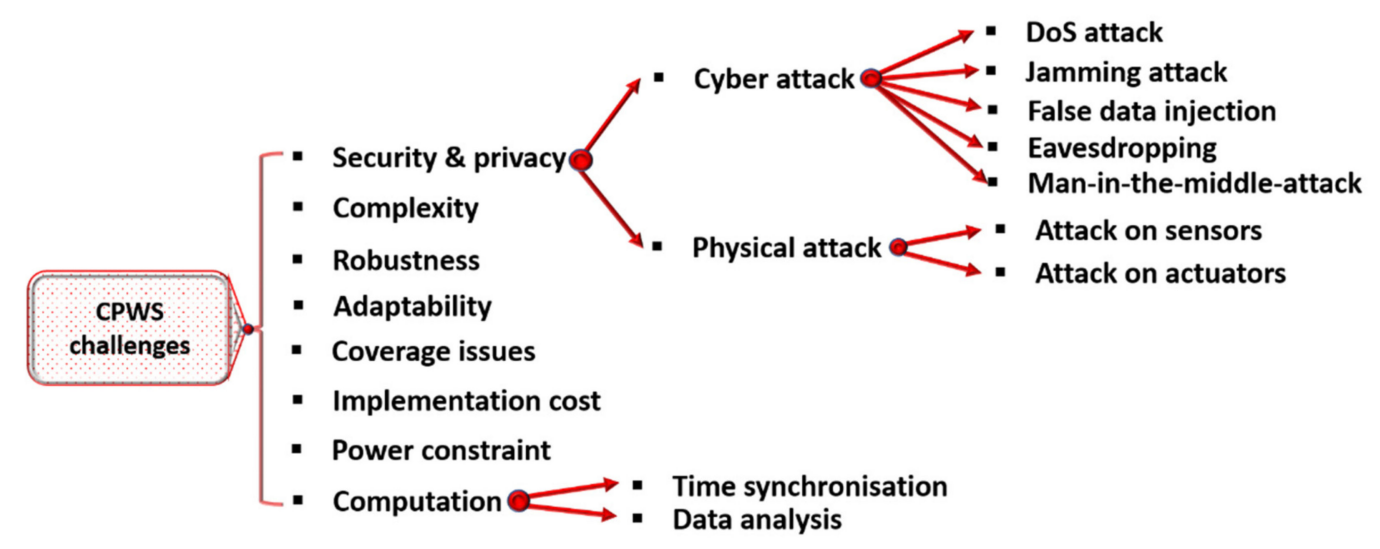

Figure 9. CPS water supply network monitoring application challenges.

\subsubsection{Robustness and Adaptability}

One of the major concern in the deployment of CPSs to monitor water supply systems facilities is the robustness of the sensing device. In a water piping network application where the sensors are exposed to severe temperature and harsh environment, the long-term durability of the sensing device is a challenge. For example, using a CPS to monitor the water quality in a water pipe network installed in a harsh underground environment, flora aggregate [111,112] may be found around the sensors, which depletes the sensing power and the operational performance of the sensing device. In extreme cases, the flora aggregate may not be easily removed, and consequently, the long-term effectiveness of the sensing device in such applications is a major concern. The effectiveness of the system thus depends on the application environments. In most cases, underwater and underground applications are a harsh environment for sensing devices. For instance, in CPS-based underground pipe leak monitoring using ground penetration radar (GPR) sensing technology, such a system is considerably affected by the type of soil in which the pipe is buried. GPR sensing technology is a technique that utilizes electromagnetic wave propagation and scattering to track a physical phenomenon. So in clay soils, corrosion products of iron pipes increase the radio frequency signal attenuation and reduce reflection [4]. Consequently, the iron pipes are masked from the GPR signal. For more information on GPR operational principle, the reader is referred to [4]. In underwater pipe leak monitoring, acoustic emission sensors are used as the sensing device. However, acoustic signals are significantly affected by background noise from the environment and those due to a pipe burst. The scheme also relies on the materials of the monitored pipe. It has been acknowledged that AE signals are well attenuated in plastic pipes [113]. Therefore, the sensing device must be robust enough to cater for these limitations. In addition, as mentioned earlier, the pattern of water demand is heavily influenced by consumer demand uncertainties and seasonal changes. As such, a CPS adopted for water quality monitoring or water supply system management must be robust and adapt quickly to responses due to water demand variations.

\subsubsection{Power Usage}

In CPS water system applications, the sensing device is a key component. A sensor essentially comprises of sensing, data processing, data storage, and a communication unit powered by a battery source. The sensors use wireless communication technology to communicate and are deployed to provide a continuous update on the state of water supply network facilities for water quality and leakage analysis, among other factors, which are anticipated to operate uninterrupted for several years. This raises the issue of energy consumption of the sensors and sensor nodes. The main sources of energy consumption by the sensor and sensor nodes are the communication task, followed by the computation and sensing tasks. During the communication task, more energy is consumed. The energy consumed during wireless transmission of a single bit of data may be about 1000 times higher than that used for a single 32-bit data computation [114]. Table 4 shows the energy consumption trend of a typical TelosB sensing platform adapted from [115]. As may be observed in Table 4 and Figure 10 [116], 
the energy consumed during the communication task is relatively higher than those consumed during data processing and storage. Additionally, the actuator nodes possess greater computational and communication capacities and a higher energy budget compared to sensors [34]. While both have power constraints problems, these key characteristics of sensors and the sensor nodes make energy consumption a key challenge in the application of a CPS for monitoring large-scale water supply systems.

Table 4. Trend of energy consumption for a typical TelosB sensing platform.

\begin{tabular}{|c|c|c|c|}
\hline Sensor Operation & Sensor Module & Mode & Measured Current (mA) \\
\hline \multirow{3}{*}{ Communications } & \multirow{3}{*}{ Radio } & Receiving & 21.8 \\
\hline & & Transmitting $(0 \mathrm{~dB})$ & 21.7 \\
\hline & & Transmitting $(-25 \mathrm{~dB})$ & 12.1 \\
\hline \multirow{2}{*}{ Data processing } & \multirow{2}{*}{ Microcontroller } & CPU active & 2.33 \\
\hline & & CPU disable & 0.0018 \\
\hline \multirow{3}{*}{ Data storage } & \multirow{3}{*}{ Internal flash memory } & Erase & 1.35 \\
\hline & & Write & $0.9-1.34$ \\
\hline & & Read & 0.68 \\
\hline
\end{tabular}

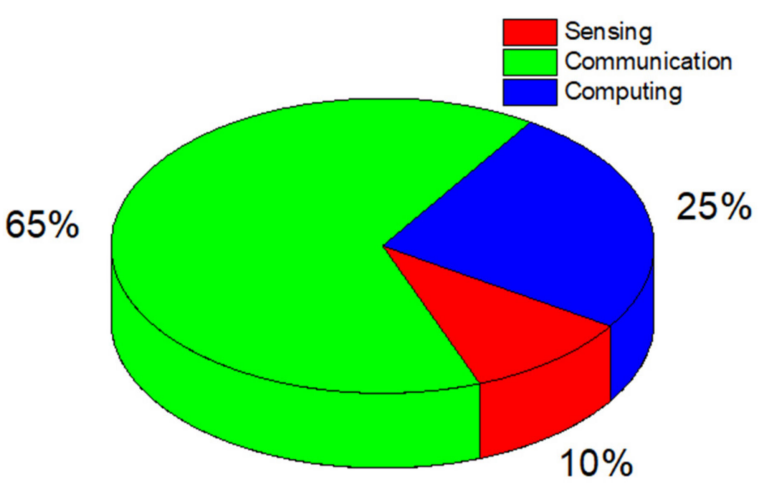

Figure 10. Energy consumption profile of a typical sensing device.

\subsubsection{System Complexity}

Water supply systems are large-scale infrastructure, thus CPSs applied to provide autonomous monitoring of the system facilities are apparently made of thousands of nodes with devices (such as sensors and actuators), which makes the configuration very complex. Modern-day water supply systems require a system to provide measurement and update for water quality, leakage detection and localization, pressure monitoring, and water demand monitoring among other factors. As such, a plethora of different sensors, each for the specific application, are needed for deployment. This increases system complexity. In addition, the system complexity is also increasing in a bid to improve the energy consumption of the sensing device and nodes by incorporating energy harvesters and some other methods for improving energy efficiency.

\subsubsection{Coverage Issue}

Sensor coverage refers to how long the measuring physical environment can be observed by the CPS sensing device. For small-scale applications such as indoor localizations [107-120], the coverage of the sensing devices may be considered insignificant. However, in water distribution network applications, which are large-scale, the coverage of sensing devices and communication technologies used is another major challenge. Since different communication technologies have different coverage areas, short-range communication technologies may need more devices to cover the same region 
covered by conventional long-range communication technologies. Therefore, coverage is one of the key challenges in the deployment of a CPS in the water supply system applications.

\subsubsection{Deployment Cost}

Water distribution networks are large-scale and complex infrastructure. As such, using a CPS for autonomous monitoring of such systems requires the deployment of a wide range of sensors to provide measurements in real time. For this application, the associated cost of deployment of the sensing device is an issue of concern. The cost of deployment concerns the cost of installing, configuring, and maintaining the sensing devices and actuators, as well as the communication protocol used by a CPS. Assuming the cost of deploying a sensing device $A$ is denoted by $C_{A}$, then in a water distribution system where several of these components are required, the deployment $\operatorname{cost}\left(\operatorname{Cost}_{D}\right)$ may be expressed as

$$
\operatorname{Cost}_{D}=\sum_{k=1}^{N} C_{A_{k}}
$$

where $N$ is used to represent the number of sensing devices needed for the specific application. Depending on the requirement of each application, Equation (1) shows that as the number of sensing devices required to provide continuous measurement increases, the associated cost of deployment also increases. This increases the cost of deploying the cyber-physical systems for water supply system applications. Thus, as the application requirements improve requiring some other sensing devices to be developed to meet the application requirements, the overall cost of deploying such a system increases.

\subsubsection{Heterogeneous Data Transmission and Analysis}

A CPS used for autonomous monitoring of water distribution networks (for leaks and water quality monitoring) generates enormous amounts of heterogeneous data from the sensing devices, which need to be analyzed and processed in an efficient way. Depending on the specific application, advanced computational tools are needed to handle the huge data and to classify and interpret the data required for each application so as to make the optimal decision as regards the state of the water system. In most water system applications of CPS, energy issues become more significant during data transmission and processing. This creates a pressing need for computational algorithms that could offer a robust but computationally less complex with lower power consumption capability. In addition, the sensors installed on the water supply distribution networks are used to provide continuous data measurement at a specific time interval. For example, in the water quality applications [26,104], this dataset needs to be synchronized and integrated with the hydraulic model in a real-time system for accurate prediction of the pollutant. Thus, accurate time synchronization of sensor data for further processing and transmission is also a major concern.

\subsubsection{Data Security and Privacy}

CPS sensing devices communicate via wireless communication technologies to enhance the system's flexibility, but due to the broadcast nature of wireless media, they pose more security risks [121,122] and are susceptible to multiple cyber-physical attacks. A cyber-attack is the attack performed via malware or access to communication network components. A physical attack directly interferes with the CPS' physical components, such as attacking the sensing and control elements. For instance, a physical attack on a CPS may include a replay attack and alteration of control statements [123,124]. Several cyber-attacks on CPSs have been reported in the literature [124-126]. Amongst others, these include eavesdropping, denial of service (DoS) attack, man-in-the-middle attack, jamming attack (aerial jamming and correlated jamming), resonance attack, false data injection (FDI), and packet modification. Eavesdropping is not a direct attack but can be considered as an intrusion or violation data privacy. An eavesdropping attack occurs when an intruder attempts to steal the water network data the CPS sensing devices transmitted over the wireless network [125]. This type 
of attack is hard to identify as it does not cause disruption to the network data transmissions. In an FDI attack, the attacker eventually infuses fake readings into smart water meters to interrupt the state estimation process of water supply systems [126]. A DoS attack [127] is the one in which the attacker sends large amounts of data to the network to make the network busy with data handling, and consequently, normal operational services cannot be achieved as the system operation is been disrupted. The man-in-the-middle attack is similar to the FDI attack. In this attack, fake messages are sent to the operator [128], resulting in the operator being able to make a choice that may not be needed, such as shutting down a section of water networks or closing a valve at the DMA inlet. The action of the operator could have triggered an undesirable incident by the time the operator follows the standard processes and tries to correct the issue. The jamming attack is considered a special case of DoS attack and is one of the serious security threats [129-131]. The attacker meddles with the normal functions of sensor nodes of the CPS by sending radio frequency signals to jam legitimate signals thereby causing a denial of service.

Several cyber-attacks on the water supply system have been reported [132-144]. Typical examples of cyber-attacks on water system infrastructure include the insider threat to Australia's Moochy Water services [132] and the one that occurred on US water system facilities [138]. Water supply systems are critical infrastructure; therefore, security and privacy of the system data should be considered essential as the CPS not only handles an enormous amount of the sensitive water system data but also has the power to influence the water supply system facilities with its control capabilities. A successful attack on a cyber-physical water system could cause a various level of havoc to the water supply system. For example, significant damage, such as long operational downtime and disruption of service, economic loss to water utilities, and a threat to public health owing to water contamination, has been reported [18]. Therefore, addressing cyber security is essential because of the significant role of the cyber-physical water system on the national economy. Researchers have made progress in developing methodologies for cyber-physical attack detection [135-148], however, they are not effective in preventing and resolving CPS security problems. Further research studies are therefore needed.

\subsection{Future Directions}

The future of cyber-physical systems is promising having enjoyed tremendous growth in industrial applications. However, the real implementation of a CPS to monitor large-scale water system infrastructure still requires a great deal of research attention. Fortunately, there is a great deal of work to build the CPS research agenda in water supply system applications. A sampling of promising research directions is outlined below.

\subsubsection{Improved Power Efficiency}

Continuous and autonomous monitoring of water supply system infrastructures requires a constant power supply for the CPS sensing and communication devices. In severe applications, such as monitoring water quality and leaks in underwater or underground pipes, enhanced battery life and optimal energy usage are highly essential. Nevertheless, energy-improving strategies such as energy harvesters [43,149-151], routing protocol algorithms [44-47,152], game-theoretic approach [153], and sensor data aggregation [154-157] have been proposed with some level of success and limitations. As the CPS water system application requirements increases, further research studies are required to develop high performance and robust energy efficient methodologies.

\subsubsection{Advanced Security Mechanism}

Water supply systems are critical infrastructure and must be protected from any kind of cyber-physical attack. Due to the growing computing power that leads to the growth of many decoding algorithms, current approaches to solving data security are not sufficient to create a substantial improvement. This creates an urgent need for new studies to develop a novel and robust security 
mechanism for cyber-physical water systems. Advanced security mechanisms for CPSs are therefore considered a hot research area.

\subsubsection{Advanced and Smart Data Transmission and Analytical Solutions}

The sensing devices in CPSs for various water supply system applications generate huge continuous and heterogeneous datasets, which must be processed and managed efficiently. Most of the current data processing methodologies are computationally complex and not power intensive. Advanced and robust data analytics solutions should further be investigated. The data analytical solutions should also consider advance lossless data compression methods. These compression methods will reduce the size of huge datasets before transmission and allow them to be retrieved without loss of information.

\subsubsection{Optimized Sensor Coverage}

Coverage of CPS sensing devices is an important issue for a reliable leakage and water quality monitoring across the complex water distribution networks in both underground, underwater, and above-ground applications. Fortunately, the design of mmWave sensors offers precise and multidimensional sensing with a capacity to penetrate materials such as plastic and drywall with good resistance to environmental conditions such as rain, fog, dust, and snow [48]. As these sensors are arranged in a sensor node connected via wireless means, more research studies should be conducted in the area of sensor network coverage optimization. As such, efficient optimization algorithms for sensor coverage enhancement should be investigated.

\subsubsection{Optimal Sensor Position}

Water distribution network monitoring is crucial. owing to the consequential effects of pipe bursts and contaminated water on public health. Intensive monitoring of the WDN pipes where sensors are placed at a strategic position under a limited budget will improve water quality and leakage awareness. In the last few years, research studies have been conducted on sensor placement under this budget constraint [158-161]. Adedoja et al. [158] presented a critical survey of the optimal sensor placement for a contaminant warning system in a water distribution network. Unfortunately, optimal placement of sensors has not been achieved under cost constraints and has received notable attention. Thus, further research studies are needed to develop efficient and rapid algorithms to solve problems related to optimal sensor position along the pipe.

\subsubsection{Advanced Control Technologies}

For effective management of water supply system facilities, an advanced control system must be integrated to in order to respond rapidly to several events in the system. Advance systems for pressure control to reduce the effect of pipe burst as well as active control valves [158] to reduce the spread of contaminant in the water distribution networks are required. Such a system must be equipped with a good response mechanism to service disaster and human error without loss of functions [162-165]. Therefore, more research studies must be conducted to develop an advanced control technology that makes CPSs respond quickly to a critical events, such as contaminant spread, leaks, the valve shut down, pipe failure, etc.. in water distribution systems.

\subsubsection{Dynamic Water Quality and Leakage Model under Demand Uncertainty}

Conventional water quality sensors could not be utilized to determine the source and spread of contaminant in the system, as such, hydraulic modelling is required. However, due to the demand uncertainties, water quality hydraulic models in a cyber-physical water system must be robust and mathematically correct. As such, more research work should be conducted to develop a novel real-time dynamic hydraulic modelling system (for water quality and leakage) that considers demand uncertainties. Modelling real-world phenomenon under demand uncertainty is a hot research area 
in the hydraulic modelling domain. Models for determining the source and spread of contaminants should also be researched and integrated into the water quality models.

\section{Conclusions}

The significant increase in intelligent devices, sensor and actuator networks, as well as computing power has resulted in swift development of systems with control and monitoring capabilities. One of these systems that have captivated the attention of researchers in recent years is the CPS. Although a CPS is complex in nature as it comprises of many heterogeneous elements such as sensors, actuators, and computing and communication platforms, its objectives are to interact with the physical environment to in order to optimized engineering operations and improve decision-making. Such systems have been applied in various industrial applications in the past and recent years. In this paper we presented the concepts of a CPS in the water supply system management context, investigated the CPS applications to water supply system monitoring, and identified the key challenges surrounding the application of a CPS in the water supply system applications. We then outlined the areas of improvement for further research studies. This paper has shown that CPSs are famous in application to water quality and leakage detection monitoring. In these applications, inherent challenges of a typical CPS have also surfaced. Amongst others, these include security and privacy of acquired water network data, sensor coverage issue for large-scale monitoring, and the energy consumption of the smart sensing devices. Most importantly, dynamic water quality and leakage modelling under the frequently changing consumer demand is also an issue of concern. These challenges are open for future research studies in this domain.

Author Contributions: K.B.A. conceived the original idea of the paper and was in charge of the manuscript draft while Y.H. helped with some improvements in the paper. All authors have read and agreed to the published version of the manuscript.

Funding: This research was funded by Tshwane University of Technology, Pretoria, South Africa.

Acknowledgments: The authors acknowledged the support from the Tshwane University of Technology, Pretoria, South Africa.

Conflicts of Interest: The authors declare no conflict of interest.

\section{References}

1. Abu-Mahfouz, A.M.; Hamam, Y.; Page, P.R.; Adedeji, K.B.; Anele, A.O.; Todini, E. Real-time dynamic hydraulic model of water distribution networks. Water 2019, 11, 470. [CrossRef]

2. Colombo, A.F.; Karney, B.W. Energy and costs of leaky pipes: Toward comprehensive picture. J. Water Resour. Plan. Manag. 2002, 128, 441-450. [CrossRef]

3. Colombo, A.F.; Karney, B.W. Impacts of leaks on energy consumption in pumped systems with storage. J. Water Resour. Plan. Manag. 2005, 131, 146-155. [CrossRef]

4. Adedeji, K.B.; Hamam, Y.; Abe, B.T.; Abu-Mahfouz, A.M. Towards achieving a reliable leakage detection and localization algorithm for application in water piping networks: An overview. IEEE Access 2017, 5 , 20272-20285. [CrossRef]

5. Covelli, C.; Cozzolino, L.; Cimorelli, L.; Della Morte, R.; Pianese, D. Reduction in water losses in water distribution systems using pressure reduction valves. Water Sci. Technol. Water Supply 2016, 16, 1033-1045. [CrossRef]

6. Adedeji, K.B.; Hamam, Y.; Abe, B.T.; Abu-Mahfouz, A.M. Leakage detection and estimation algorithm for loss reduction in water piping networks. Water 2017, 9, 773. [CrossRef]

7. Giudicianni, C.; Herrera, M.; di Nardo, A.; Carravetta, A.; Ramos, H.M.; Adeyeye, K. Zero-net energy management for the monitoring and control of dynamically-partitioned smart water systems. J. Clean. Prod. 2020, 252, 119745. [CrossRef]

8. AWWA. Applying worldwide BMPs in water loss control. J. Am. Water Work. Assoc. 2003, 95, 65-79. [CrossRef]

9. Sun, C.; Cembrano, G.; Puig, V.; Meseguer, J. Cyber-physical systems for real-time management in the urban water cycle. In Proceedings of the IEEE International Workshop on Cyber-Physical Systems for Smart Water Networks, Porto, Portugal, 10 April 2018; pp. 5-8. 
10. Fan, Y.; Li, J.; Zhang, D.; Pi, J.; Song, J.; Zhao, G. Supporting sustainable maintenance of substations under cyber-threats: An evaluation method of cybersecurity risk for power CPS. Sustainability 2019, 11, 982. [CrossRef]

11. Kao, H.A.; Jin, W.; Siegel, D.; Lee, J. A cyber physical interface for automation systems-Methodology and examples. Machines 2015, 3, 93-106. [CrossRef]

12. Imen, S.; Chang, N.B. Developing a cyber-physical system for smart and sustainable drinking water infrastructure management. In Proceedings of the IEEE 13th International Conference on Networking, Sensing, and Control, Mexico City, Mexico, 28-30 April 2016; pp. 1-6.

13. Xiong, G.; Zhu, F.; Liu, X.; Dong, X.; Huang, W.; Chen, S.; Zhao, K. Cyber-physical-social system in intelligent transportation. IEEE/CAA J. Autom. Sin. 2015, 2, 320-333.

14. Mois, G.; Sanislav, T.; Folea, S.C. A cyber-physical system for environmental monitoring. IEEE Trans. Instrum. Meas. 2016, 65, 1463-1471. [CrossRef]

15. Lang, X.; Li, P.; Li, Y.; Ren, H. Leak location of pipeline with multibranch based on a cyber-physical system. Information 2017, 8, 113. [CrossRef]

16. Lambrou, T.P.; Anastasiou, C.C.; Panayiotou, C.G.; Polycarpou, M.M. A low-cost sensor network for real-time monitoring and contamination detection in drinking water distribution systems. IEEE Sens. J. 2014, 14, 2765-2772. [CrossRef]

17. Yao, X.; Zhou, J.; Lin, Y.; Li, Y.; Yu, H.; Liu, Y. Smart manufacturing based on cyber-physical systems and beyond. J. Intell. Manuf. 2019, 30, 2805-2817. [CrossRef]

18. Nikolopoulos, D.; Makropoulos, C.; Kalogeras, D.; Monokrousou, K.; Tsoukalas, I. Developing a stress-testing platform for cyber-physical water infrastructure. In Proceedings of the IEEE International Workshop on Cyber-Physical Systems for Smart Water Networks, Porto, Portugal, 10 April 2018; pp. 9-11.

19. Lee, J.; Bagheri, B.; Kao, H.A. A cyber physical systems architecture for industry 4.0-based manufacturing systems. Manuf. Lett. 2015, 3, 18-23. [CrossRef]

20. Karagiannidis, L.; Vrettopoulos, M.; Amditis, A.; Makri, E.; Gkonos, E. A CPS-enabled architecture for sewer mining systems. In Proceedings of the IEEE International Workshop on Cyber-Physical Systems for Smart Water Networks, Vienna, Austria, 11 April 2016; pp. 1-6.

21. Akanmu, A.; Anumba, C.J.; Messner, J.I. An RTLS-based approach to cyber-physical systems integration in design and construction. Int. J. Distrib. Sens. Netw. 2012, 8, 1-11. [CrossRef]

22. Khan, M.U.; Li, S.; Wang, Q.; Shao, Z. CPS oriented control design for networked surveillance robots with multiple physical constraints. IEEE Trans. Comput. Aided Des. Integr. Circuits Syst. 2016, 35, 778-791. [CrossRef]

23. Dong, J.; Xiao, T.; Zhang, L. A prototype architecture for assembly-oriented cyber-physical systems. In Proceedings of the 2012 Asian Simulation Conference, Shanghai, China, 27-30 October 2012; Springer: Berlin/Heidelberg, Germany, 2012; pp. 199-204.

24. Xiao-Le, W.; Hong-Bin, H.; Su, D.; Li-Na, C. A service-oriented architecture framework for cyber-physical systems. In Recent Advances in Computer Science and Information Engineering, Lecture Notes in Electrical Engineering, 2; Qian, Z., Cao, L., Su, W., Wang, T., Yang, H., Eds.; Springer-Verlag: Berlin/Heidelberg, Germany, 2012; pp. 671-676.

25. Chen, H. Applications of cyber-physical system: A literature review. J. Ind. Integr. Manag. 2017, 2, 1-28. [CrossRef]

26. Wang, Z.; Song, H.; Watkins, D.W.; Ong, K.G.; Xue, P.; Yang, Q.; Shi, X. Cyber-physical systems for water sustainability: Challenges and opportunities. IEEE Commun. Mag. 2015, 5, 216-222. [CrossRef]

27. Nathanson. Water Supply System. Available online: https://www.britannica.com/technology/water-supplysystem/Chlorination (accessed on 23 May 2019).

28. Mamade, A.; Loureiroa, D.; Covasb, D.; Alegrea, H. Energy auditing as a tool for improving service efficiency of water supply systems. Procedia Eng. 2014, 89, 557-564. [CrossRef]

29. ERSAR. Evaluation of Service Quality Provided to the Users; ERSAR: Lisbon, Portugal, 2011.

30. Guyer, J.P. Introduction to Pumping Stations for Water Supply Systems; Continuing Education and Development Inc.: New York, NY, USA, 2012.

31. Palviainen, M.; Mantyjarvi, J.; Rnokainen, J.; Tuomikoski, M. Towards user-friendly cyber-physical systems-strategies to support user intervention in provisioning of information and capabilities of cyber-physical systems. In Industrial Internet of Things; Jeschke, S., Brecher, C., Song, H., Rawat, D., Eds.; Springer Series in Wireless Technology; Springer: Cham, Switzerland, 2017; pp. 575-593.

32. Hoang, D.D.; Kim, H.K. Service-oriented middleware architectures for cyber-physical systems. Int. J. Comput. Sci. Netw. Secur. 2012, 12, 79-87. 
33. Tan, Y.; Goddard, S.; Pérez, L.C. A prototype architecture for cyber-physical systems. ACM Sigbed Rev. 2008, 5, 1-2. [CrossRef]

34. Xia, F. QoS challenges and opportunities in wireless sensor/actuator networks. Sensors 2008, 8, 1099-1110. [CrossRef] [PubMed]

35. Maglaras, L.A.; Katsaros, D. New measures for characterizing the significance of nodes in wireless ad hoc networks via localized path-based neighbourhood analysis. Soc. Netw. Anal. Min. 2012, 2,97-106. [CrossRef]

36. Mustafa, H.; Chou, P.H. Embedded damage detection in water pipelines using wireless sensor networks. In Proceedings of the 9th IEEE International Conference on High Performance Computing and Communication \& the 14th IEEE International Conference on Embedded Software and Systems, Liverpool, UK, 25-27 June 2012; pp. 1578-1586.

37. Sun, Z.; Wang, P.; Vuran, M.C.; Al-Rodhaan, M.A.; Al-Dhelaan, A.M.; Akyildiz, I.F. MISE-PIPE: Magnetic induction-based wireless sensor networks for underground pipeline monitoring. Ad Hoc Netw. 2011, 9, 218-227. [CrossRef]

38. Aziz, A.B.; Mohemmed, N.A.B.; Alias, M.Y. A wireless sensor network coverage optimization algorithm based on particle swarm optimization and Voronoi diagram. In Proceedings of the IEEE International Conference on Networking, Sensing and Control, Okayama, Japan, 26-29 March 2009; pp. 602-607.

39. Zhou, S.; Wu, M.Y.; Shu, W. Improving mobile target detection on randomly deployed sensor networks. Int. J. Sens. Netw. 2009, 6, 115-128. [CrossRef]

40. Chen, J.; Li, J.; He, S.; Sun, Y.; Chen, H.H. Energy-efficient coverage based on probabilistic sensing model in wireless sensor networks. IEEE Commun. Lett. 2010, 14, 833-835. [CrossRef]

41. Li, J.H.; Yu, M. Sensor coverage in wireless ad hoc sensor networks. Int. J. Sens. Netw. 2007, 2, 218-229. [CrossRef]

42. Jan, N.; Javaid, N.; Javaid, Q.; Alrajeh, N.A.; Alam, M.; Khan, Z.A.; Niaz, I.A. A balanced energy consuming and hole alleviating algorithm for wireless sensor networks. IEEE Access 2017, 5, 6134-6150. [CrossRef]

43. Nishimoto, H.; Kawahara, Y.; Asami, T. Prototype implementation of ambient RF energy harvesting wireless sensor networks. In Proceedings of the IEEE Sensors Conference, Waikoloa, HI, USA, 1-4 November 2010; pp. 1282-1287.

44. Karim, L.; Nasser, N.; Sheltami, T. A fault-tolerant energy-efficient clustering protocol of a wireless sensor network. Wirel. Commun. Mob. Comput. 2014, 14, 175-185. [CrossRef]

45. Liu, Z.; Zheng, Q.; Xue, L.; Guan, X. A distributed energy-efficient clustering algorithm with improved coverage in wireless sensor networks. Future Gener. Comput. Syst. 2012, 28, 780-790. [CrossRef]

46. Cardei, M.; Du, D.Z. Improving wireless sensor network lifetime through power aware organization. Wirel. Netw. 2005, 11, 333-340. [CrossRef]

47. Abo-Zahhad, M.; Ahmed, S.M.; Sabor, N.; Sasaki, S. Mobile sink-based adaptive immune energy-efficient clustering protocol for improving the lifetime and stability period of wireless sensor networks. IEEE Sens. J. 2012, 15, 4576-4586. [CrossRef]

48. Texas Instrument. Single-Chip 60-GHz to 64-GHz Intelligent mmWave Sensor Integrating Processing Capability; Texas Instrument Inc.: Dallas, TX, USA, 2019.

49. Want, R. An introduction to RFID technology. IEEE Pervasive Comput. 2006, 1, 25-33. [CrossRef]

50. Federal Communications Commission. Revision of Part 15 of the Commission's Rules Regarding Ultra-Wideband Transmission Systems, First Report and Order, ET Docket 98-153, FCC 02-48, April 2002. Available online: http://www.fcc.gov (accessed on 10 May 2019).

51. Rahayu, Y.; Rahman, T.A.; Ngah, R.; Hall, P.S. Ultra-wideband technology and its applications. In Proceedings of the IEEE 5th IFIP International Conference on Wireless and Optical Communications Networks, Surabaya, Indonesia, 5-7 May 2008; pp. 1-5.

52. Woodman, O.; Harle, R. Pedestrian localisation for indoor environments. In Proceedings of the 10th ACM International Conference on Ubiquitous Computing, Seoul, Korea, 21-24 September 2008; pp. 114-123.

53. Dar, K.; Bakhouya, M.; Gaber, J.; Wack, M.; Lorenz, P. Wireless communication technologies for ITS applications. IEEE Commun. Mag. 2010, 48, 156-162. [CrossRef]

54. Akpakwu, G.A.; Silva, B.J.; Hancke, G.P.; Abu-Mahfouz, A.M. A survey on 5G networks for the internet of things: Communication technologies and challenges. IEEE Access 2017, 6, 3619-3647. [CrossRef]

55. Coskun, V.; Ozdenizci, B.; Ok, K. A survey on near field communication technology. Wirel. Pers. Commun. 2013, 71, 2259-2294. [CrossRef] 
56. Weyn, M.; Ergeerts, G.; Wante, L.; Vercauteren, C.; Hellinckx, P. Survey of the DASH7 alliance protocol for $433 \mathrm{MHz}$ wireless sensor communication. Int. J. Distrib. Sens. Netw. 2013, 9, 870430. [CrossRef]

57. Cetinkaya, O.; Akan, O.B. A DASH7-based power metering system. In Proceedings of the 12th IEEE Annual IEEE Consumer Communications and Networking, Las Vegas, NV, USA, 9-12 January 2015; pp. 406-411.

58. Mekki, K.; Bajic, E.; Chaxel, F.; Meyer, F. A comparative study of LPWAN technologies for large-scale IoT deployment. Ict Express 2019, 5, 1-7. [CrossRef]

59. Song, Y.; Lin, J.; Tang, M.; Dong, S. An Internet of energy things based on wireless LPWAN. Engineering 2017, 3, 460-466. [CrossRef]

60. 3GPP. Standardization of NB-IoT Completed June 2016. Available online: https://www.3gpp.org/newsevents/3gpp-news/1785-nb_iot_complete (accessed on 28 May 2019).

61. GSMA: 3GPP Low Power Wide Area Technologies. GSMA White Paper. Available online: https://www.gsma. com/iot/wp-content/uploads/2016/10/3GPP-Low-Power-Wide-Area-Technologies-GSMA-White-Paper.pdf (accessed on 28 May 2019).

62. Atiquzzaman, M.D.; Shie-Yui, L.; Xinying, Y. Alternative decision making in water distribution network with NSGA-II. J. Water Resour. Plan. Manag. 2006, 132, 122-126. [CrossRef]

63. Fu, G.; Kapelan, Z.; Kasprzyk, J.R.; Reed, P. Optimal design of water distribution systems using many-objective visual analytics. J. Water Resour. Plan. Manag. 2012, 139, 624-633. [CrossRef]

64. Nasiri, F.; Maqsood, I.; Huang, G.; Fuller, N. Water quality index: A fuzzy river-pollution decision support expert system. J. Water Resour. Plan. Manag. 2007, 133, 95-105. [CrossRef]

65. Velasquez, M.; Hester, P.T. An analysis of multi-criteria decision making methods. Int. J. Oper. Res. 2013, 10, 56-66.

66. Brill, E. Implementing machine learning algorithms for water quality event detection: Theory and practice. In Securing Water and Wastewater Systems, Protecting Critical Infrastructure 2; Clark, R.M., Hakim, S., Eds.; Springer International Publishing: Cham, Switzerland, 2014; Chapter 4; pp. 107-122.

67. Towler, E.; Roberts, M.; Rajagopalan, B.; Sojda, R.S. Incorporating probabilistic seasonal climate forecasts into river management using a risk-based framework. Water Resour. Res. 2013, 49, 4997-5008. [CrossRef]

68. Bucovetchi, O.; Georgescu, A.; Badea, D.; Stanciu, R.D. Agent-based modelling (ABM): Support for emphasizing the air transport infrastructure dependence of space systems. Sustainability 2019, 11, 5331. [CrossRef]

69. Akhbari, M.; Grigg, N.S. A framework for an agent-based model to manage water resources conflicts. Water Resour. Manag. 2013, 27, 4039-4052. [CrossRef]

70. Athanasiadis, N.I.; Mentes, A.K.; Mitkas, P.A.; Mylopoulos, Y.A. A hybrid agent-based model for estimating residential water demand. Simulation 2005, 81, 175-187. [CrossRef]

71. Zechman, E.M. Agent-based modelling to simulate contamination events and evaluate threat management strategies in water distribution systems. Risk Anal. 2011, 31, 758-772. [CrossRef]

72. Shafiee, M.E.; Zechman, E.M. An agent-based modelling framework for sociotechnical simulation of water distribution contamination events. J. Hydroinform. 2013, 15, 862-880. [CrossRef]

73. Huber, L.; Bahro, N.; Leitinger, G.; Tappeiner, U.; Strasser, U. Agent-based modelling of a coupled water demand and supply system at the catchment scale. Sustainability 2019, 11, 6178. [CrossRef]

74. Mashford, J.; De Silva, G.; Burn, D.; Marney, D. Leak detection in simulated water pipe networks using SVM. Appl. Artif. Intell. 2012, 26, 429-444. [CrossRef]

75. Liu, C.; Ghosal, S.; Jiang, Z.; Sarkar, S. An unsupervised spatiotemporal graphical modelling approach to anomaly detection in distributed CPS. In Proceedings of the ACM/IEEE 7th International Conference on Cyber-Physical Systems, Vienna, Austria, 11-14 April 2016; pp. 1-10.

76. Zhang, Q.; Wu, Z.Y.; Zhao, M.; Qi, J.; Huang, Y.; Zhao, H. Leakage zone identification in large-scale water distribution systems using multiclass support vector machines. J. Water Resour. Plan. Manag. 2016, 142, 1-15. [CrossRef]

77. Beck, S.B.; Curren, M.D.; Sims, N.D.; Stanway, R. Pipeline network features and leak detection by cross-correlation analysis of reflected waves. J. Hydraul. Eng. 2005, 131, 715-723. [CrossRef]

78. Gao, Y.; Brennan, M.J.; Joseph, P.F.; Muggleton, J.M.; Hunaidi, O. A model of the correlation function of leak noise in buried plastic pipes. J. Sound Vib. 2014, 277, 133-148. [CrossRef]

79. Caputo, C.A.; Pelagagge, P.M. Using neural networks to monitor piping systems. Process Saf. Prog. 2003, 22, 119-127. [CrossRef] 
80. Zhang, Z.W.; Ye, H.; Wang, G.Z.; Yang, J. Leak detection in transport pipelines using enhanced independent component analysis and support vector machines. Adv. Nat. Comput. Lect. Notes Comput. Sci. 2005, 3611, 95-100.

81. Christodoulou, S.E.; Kourti, E.; Agathokleous, A. Waterloss detection in water distribution networks using wavelet change-point detection. Water Resour. Manag. 2017, 31, 979-994. [CrossRef]

82. Yang, S.; Bagheri, B.; Kao, H.A.; Lee, J. A unified framework and platform for designing of cloud-based machine health monitoring and manufacturing systems. J. Manuf. Sci. Eng. 2015, 137, 409-414. [CrossRef]

83. Dogaru, D.I.; Dumitrache, I. Cyber-physical systems in healthcare networks. In Proceedings of the IEEE E-Health and Bioengineering Conference, Iasi, Romania, 19-21 November 2015; pp. 1-4.

84. Li, Y.T.; Jacob, M.; Akingba, G.; Wachs, J.P. A cyber-physical management system for delivering and monitoring surgical instruments in the OR. Surg. Innov. 2013, 20, 377-384. [CrossRef] [PubMed]

85. Sanislav, T.; Mois, G.; Folea, S.; Miclea, L.; Gambardella, G.; Prinetto, P. A cloud-based Cyber-Physical System for environmental monitoring. In Proceedings of the IEEE 3rd Mediterranean Conference on Embedded Computing, Budva, Montenegro, 15-19 June 2014; pp. 6-9.

86. Basile, F.; Chiacchio, P.; Coppola, J.; Gerbasio, D. Automated warehouse systems: A cyber-physical system perspective. In Proceedings of the IEEE 20th Conference on Emerging Technologies \& Factory Automation, Luxembourg, 8-11 September 2015; pp. 1-4.

87. Sridhar, S.; Hahn, A.; Govindarasu, M. Cyber-physical system security for the electric power grid. Proc. IEEE 2012, 100, 210-224. [CrossRef]

88. Yu, X.; Xue, Y. Smart grids: A cyber-physical systems perspective. Proc. IEEE 2016, 104, 1058-1070. [CrossRef]

89. Sampigethaya, K.; Poovendran, R. Cyber-physical system framework for future aircraft and air traffic control. In Proceedings of the IEEE Aerospace Conference, Big Sky, MT, USA, 3-10 March 2012; pp. 1-9.

90. Sampigethaya, K.; Poovendran, R. Aviation cyber-physical systems: Foundations for future aircraft and air transport. Proc. IEEE 2013, 101, 1834-1855. [CrossRef]

91. Tseng, Y.C.; Pan, M.S.; Tsai, Y.Y. Wireless sensor networks for emergency navigation. Computer 2006, 39, 55-62. [CrossRef]

92. Niu, H.; Jagannathan, S. Optimal defense and control of dynamic systems modelled as cyber-physical systems. J. Def. Model. Simul. 2015, 12, 423-438. [CrossRef]

93. Chen, J.; Kwong, K.; Chang, D.; Luk, J.; Bajcsy, R. Wearable sensors for reliable fall detection. In Proceedings of the 27th IEEE Conference of the Engineering in Medicine and Biology Society, Shanghai, China, 1-4 September 2005; pp. 3551-3554.

94. Mehdipour, F.; Nunna, K.C.; Murakami, K.J. A smart cyber-physical systems-based solution for pest control. In Proceedings of the 2013 IEEE and Internet of Things (iThings/CPSCom), IEEE Internetional Conference and IEEE Cyber, Physical and Social Computing, Beijing, China, 20-23 August 2013; pp. 1248-1253.

95. Tian, C.H.; Yan, J.C.; Huang, J.; Wang, Y.; Kim, D.S.; Yi, T. Negative pressure wave- based pipeline leak detection: Challenges and algorithms. In Proceedings of the of the IEEE International Conference on Service Operations and Logistics, and Informatics, Suzhou, China, 8-10 July 2012; pp. 372-376.

96. Stankovic, J.A.; Lee, I.; Mok, A.; Rajkumar, R. Opportunities and obligations for physical computing systems. IEEE Comput. Soc. 2005, 38, 23-31. [CrossRef]

97. WHO. Guidelines for Drinking Water Quality, 4th ed.; World Health Organization Press: Geneva, Switzerland, 2011.

98. Adu-Manu, K.S.; Tapparello, C.; Heinzelman, W.; Katsriku, F.A.; Abdulai, J.D. Water quality monitoring using wireless sensor networks: Current trends and future research directions. ACM Trans. Sens. Netw. 2017, 13, 1-41. [CrossRef]

99. Yue, R.; Ying, T. A water quality monitoring system based on wireless sensor network and solar power supply. In Proceedings of the IEEE International Conference on Cyber Technology in Automation, Control, and Intelligent Systems, Kunming, China, 20-23 March 2011; pp. 126-129.

100. Bhardwaj, J.; Gupta, K.K.; Gupta, R. Towards a cyber-physical era: Soft computing framework based multi-sensor array for water quality monitoring. Drink. Water Eng. Sci. 2018, 11, 9-17. [CrossRef]

101. Ge, F.; Wang, Y. Energy efficient networks for monitoring water quality in subterranean rivers. Sustainability 2016, 8, 526. [CrossRef]

102. Grayman, W.M.; Murray, R.; Savic, D.A. Effects of redesign of water systems for security and water quality factors. In Proceedings of the World Environmental and Water Resources Congress, Kansas City, MI, USA, 17-21 May 2009; pp. 1-11. 
103. Ciaponi, C.; Creaco, E.; Di Nardo, A.; Di Natale, M.; Giudicianni, C.; Musmarra, D.; Santonastaso, G.F. Reducing impacts of contamination in water distribution networks: A combined strategy based on network partitioning and installation of water quality sensors. Water 2019, 11, 1315. [CrossRef]

104. Nasir, A.; Soong, B.H.; Ramachandran, S. Framework of WSN based human centric cyber physical in-pipe water monitoring system. In Proceedings of the IEEE 11th International Conference on Control Automation Robotics \& Vision, Singapore, 7-10 December 2010; pp. 1257-1261.

105. Nasir, A.; Soong, B.H. PipeSense: A framework architecture for in-pipe water monitoring system. In Proceedings of the IEEE 9th Malaysia International Conference on Communications, Kuala Lumpur, Malaysia, 14-17 December 2009; pp. 703-708.

106. Kartakis, S.; Abraham, E.; McCann, J.A. Waterbox: A testbed for monitoring and controlling smart water networks. In Proceedings of the 1st ACM International Workshop on Cyber-Physical Systems for Smart Water Networks, Seattle, WA, USA, 13 April 2015; p. 8.

107. Hu, J.; Zhang, L.; Wang, Z.; Liang, W. Application of an improved ISODATA method to pipeline leak detection. Pet. Sci. 2007, 4, 97-104.

108. Mounce, S.R.; Machell, J. Burst detection using hydraulic data from water distribution systems with artificial neural networks. Urban Water J. 2006, 3, 21-31. [CrossRef]

109. Arsene, C.T.; Gabrys, B.; Al-Dabass, D. Decision support system for water distribution systems based on neural networks and graphs theory for leakage detection. Expert Syst. Appl. 2012, 39, 13214-13224. [CrossRef]

110. Islam, M.S.; Sadiq, R.; Rodriguez, M.J.; Francisque, A.; Najjaran, H.; Hoorfar, M. Leakage detection and location in water distribution systems using a fuzzy-based methodology. Urban Water J. 2011, 8, 351-365. [CrossRef]

111. Choi, C.H.; Scardino, A.J.; Dylejko, P.G.; Fletcher, L.E.; Juniper, R. The effect of vibration frequency and amplitude on biofouling deterrence. Biofouling 2013, 29, 195-202. [CrossRef]

112. Bearinger, J.P.; Terrettaz, S.; Michel, R. Sulfamer block copolymers protection of gold surfaces. Nat. Mater. 2003, 2, 257-264.

113. Yang, J.; Wen, Y.; Li, P. Leak location using blind system identification in water distribution pipelines. J. Sound Vib. 2008, 310, 134-148. [CrossRef]

114. Barr, B.C.; Asanović, K. Energy-aware lossless data compression. ACM Trans. Comput. Syst. 2006, 24, 250-291. [CrossRef]

115. Prayati, A.; Antonopoulos, C.; Stoyanova, T.; Koulamas, C.; Papadopoulos, G. A modelling approach on the TelosB WSN platform power consumption. J. Syst. Softw. 2010, 83, 1355-1363. [CrossRef]

116. Costarella, D. Development of a wireless sensor network powered by energy harvesting techniques. In Proceedings of the Workshop on Better Embedded, Florence, Italy, 9 July 2013.

117. Bilke, A.; Sieck, J. Using the magnetic field for indoor localisation on a mobile phone. In Progress in Location-Based Services; Springer: Berlin/Heidelberg, Germany, 2013; pp. 195-208.

118. Ropponen, A.; Rimminen, H.; Sepponen, R. Robust system for indoor localisation and identification for the health care environment. Wirel. Pers. Commun. 2011, 59, 57-71. [CrossRef]

119. Ros, M.; Boom, J.; de Hosson, G.; D'Souza, M. Indoor localisation using a context-aware dynamic position tracking model. Int. J. Navig. Obs. 2012, 2012, 1-12. [CrossRef]

120. Lau, S.L.; Xu, Y.; David, K. Novel indoor localisation using an unsupervised Wi-Fi signal clustering method. In Proceedings of the IEEE Future Network \& Mobile Summit, Warsaw, Poland, 15-17 June 2011; pp. 1-8.

121. Liu, Y.; Dong, M.; Ota, K.; Liu, A. ActiveTrust: Secure and trustable routing in wireless sensor networks. IEEE Trans. Inf. Forensics Secur. 2016, 11, 2013-2027. [CrossRef]

122. Song, J.; Lee, Y.; Choi, J.; Gil, J.; Han, J.; Choi, S. Practical in-depth analysis of IDS alerts for tracing and identifying potential attackers on darknet. Sustainability 2017, 9, 262. [CrossRef]

123. Chen, B.; Ho, D.W.; Hu, G.; Yu, L. Secure fusion estimation for bandwidth constrained cyber-physical systems under replay attacks. IEEE Trans. Cybern. 2017, 48, 1862-1876. [CrossRef]

124. Hoehn, A.; Zhang, P. Detection of replay attacks in cyber-physical systems. In Proceedings of the 2016 IEEE American Control Conference, Boston, MA, USA, 6-8 July 2016; pp. 290-295.

125. Kao, J.; Marculescu, R. Eavesdropping minimization via transmission power control in Ad-Hoc wireless networks. In Proceedings of the 3rd Annual IEEE Communications Society on Sensor and Ad Hoc Communications and Networks, Reston, VA, USA, 25-28 September 2006.

126. Deng, R.; Zhuang, P.; Liang, H. False data injection attacks against state estimation in power distribution systems. IEEE Trans. Smart Grid 2019, 10, 2871-2881. [CrossRef] 
127. Pelechrinis, K.; Iliofotou, M. Denial of Service Attacks in Wireless Networks: The Case of Jammers; UC Riverside Department of Computer Science and Engineering: Riverside, CA, USA, 2006.

128. Saltzman, R.; Sharabani, A. Active Man in the Middle Attacks, a Security Advisory A Whitepaper from IBM Rational Application Security Group; IBM Corporation: New York, NY, USA, 27 February 2009.

129. Li, Y.; Shi, L.; Cheng, P.; Chen, J.; Quevedo, D.E. Jamming attacks on remote state estimation in cyber-physical systems: A game-theoretic approach. IEEE Trans. Autom. Control 2015, 60, 2831-2836. [CrossRef]

130. Mpitziopoulos, A.; Gavalas, D.; Konstantopoulos, C.; Pantziou, G. A survey on jamming attacks and countermeasures in WSNs. IEEE Commun. Surv. Tutor. 2009, 11, 42-56. [CrossRef]

131. Osanaiye, O.; Alfa, A.; Hancke, G. A statistical approach to detect jamming attacks in wireless sensor networks. Sensors 2018, 18, 1691. [CrossRef]

132. Slay, J.; Miller, M. Lessons Learned from the Maroochy Water Breach; Springer: Berlin, Germany, 2008.

133. Dakin, D.; Newman, R.; Groves, D. The case for cyber security in the water sector. J. Am. Water Work. Assoc. 2009, 101, 30-32.

134. Amin, S.; C'ardenas, A.; Sastry, S. Safe and secure networked control systems under denial-of-service attacks. In Proceedings of the 12th International Conference on Hybrid Systems: Computation and Control, San Francisco, CA, USA, 13-15 April 2009; pp. 31-45.

135. Amin, S.; Litrico, X.; Sastry, S.S.; Bayen, A.M. Stealthy deception attacks on water SCADA systems. In Proceedings of the Hybrid Systems: Computation and Control, Stockholm, Sweden, 12-16 April 2010; pp. 161-170.

136. Taormina, R.; Galelli, S.; Tippenhauer, N.O.; Salomons, E.; Ostfeld, A. Characterizing cyberphysical attacks on water distribution systems. J. Water Resour. Plan. Manag. 2017, 143, 04017009. [CrossRef]

137. Taormina, R.; Galelli, S.; Douglas, H.C.; Tippenhauer, N.O.; Salomons, E.; Ostfeld, A. Modelling cyber-physical attacks on water networks with EpanetCPA. In Proceedings of the 1st International WDSA/CCWI 2018 Joint Conference, Kingston, ON, Canada, 23-25 July 2018.

138. ICS-CERT. NCCIC/ICS-CERT Year in Review: FY 2015; Report No. 15e50569; U.S. Department of Homeland Security e-Industrial Control Systems-Cyber Emergency Response Team: Washington, DC, USA, 2016.

139. Abokifa, A.A.; Haddad, K.; Lo, C.S.; Biswas, P. Detection of cyber physical attacks on water distribution systems via principal component analysis and artificial neural networks. In Proceedings of the World Environmental and Water Resources Congress, Sacramento, CA, USA, 21-25 May 2017; pp. 676-691.

140. Taormina, R.; Galelli, S.; Tippenhauer, N.O.; Salomons, E.; Ostfeld, A.; Eliades, D.G.; Brentan, B.M. Battle of the attack detection algorithms: Disclosing cyber-attacks on water distribution networks. J. Water Resour. Plan. Manag. 2018, 144, 04018048. [CrossRef]

141. Taormina, R.; Galelli, S. Deep-learning approach to the detection and localization of cyber-physical attacks on water distribution systems. J. Water Resour. Plan. Manag. 2018, 144, 04018065. [CrossRef]

142. Housh, M.; Ohar, Z. Model-based approach for cyber-physical attack detection in water distribution systems. Water Res. 2018, 139, 132-143. [CrossRef]

143. Taormina, R.; Galelli, S.; Douglas, H.C.; Tippenhauer, N.O.; Salomons, E.; Ostfeld, A. A toolbox for assessing the impacts of cyber-physical attacks on water distribution systems. Environ. Model. Softw. 2019, 112, 46-51. [CrossRef]

144. Abokifa, A.A.; Haddad, K.; Lo, C.; Biswas, P. Real-time identification of cyber-physical attacks on water distribution systems via machine learning-based anomaly detection techniques. J. Water Resour. Plan. Manag. 2019, 145, 04018089. [CrossRef]

145. Rasekh, A.; Hassanzadeh, A.; Mulchandani, S.; Modi, S.; Banks, M.K. Smart water networks and cyber security. J. Water Resour. Plan. Manag. 2016, 142, 1-3. [CrossRef]

146. Pasqualetti, F.; Dörfler, F.; Bullo, F. Attack detection and identification in cyber-physical systems. IEEE Trans. Autom. Control 2013, 58, 2715-2729. [CrossRef]

147. Amin, S.; Litrico, X.; Sastry, S.; Bayen, A.M. Cyber security of water SCADA systems-Part II: Attack detection using enhanced hydrodynamic models. IEEE Trans. Control Syst. Technol. 2012, 21, 1679-1693. [CrossRef]

148. Amin, S.; Litrico, X.; Sastry, S.; Bayen, A.M. Cyber security of water SCADA systems-Part I: Analysis and experimentation of stealthy deception attacks. IEEE Trans. Control Syst. Technol. 2012, 21, 1963-1970. [CrossRef]

149. Vullers, R.J.; Van Schaijk, R.; Visser, H.J.; Penders, J.; Van Hoof, C. Energy harvesting for autonomous wireless sensor networks. IEEE Solid State Circuits Mag. 2010, 2, 29-38. [CrossRef] 
150. Jettanasen, C.; Songsukthawan, P.; Ngaopitakkul, A. Development of micro-mobility based on piezoelectric energy harvesting for smart city applications. Sustainability 2020, 12, 2933. [CrossRef]

151. Khaligh, A.; Zeng, P.; Zheng, C. Kinetic energy harvesting using piezoelectric and electromagnetic technologies—state of the art. IEEE Trans. Ind. Electron. 2009, 57, 850-860. [CrossRef]

152. Niyato, D.; Hossain, E.; Rashid, M.M.; Bhargava, V.K. Wireless sensor networks with energy harvesting technologies: A game-theoretic approach to optimal energy management. IEEE Wirel. Commun. 2007, 14, 90-96. [CrossRef]

153. AlSkaif, T.; Zapata, M.G.; Bellalta, B. Game theory for energy efficiency in wireless sensor networks: Latest trends. J. Netw. Comput. Appl. 2015, 54, 33-61. [CrossRef]

154. Castelluccia, C.; Mykletun, E.; Tsudik, G. Efficient aggregation of encrypted data in wireless sensor networks. In Proceedings of the 2nd IEEE Annual International Conference on Mobile and Ubiquitous Systems: Networking and Services, San Diego, CA, USA, 17-21 July 2005; pp. 109-117.

155. Xiang, L.; Luo, J.; Vasilakos, A.V. Compressed data aggregation for energy efficient wireless sensor networks. In Proceedings of the 8th Annual IEEE Communications Society Conference on Sensor, Mesh and Ad hoc Communications and Networks, Salt Lake City, UT, USA, 20-30 June 2011; pp. 46-54.

156. Kalpakis, K.; Dasgupta, K.; Namjoshi, P. Efficient algorithms for maximum lifetime data gathering and aggregation in wireless sensor networks. Comput. Netw. 2003, 42, 697-716. [CrossRef]

157. Rodríguez-Robles, J.; Martin, A.; Martin, S.; Ruipérez-Valiente, J.A.; Castro, M. Autonomous sensor network for rural agriculture environments, low cost, and energy self-charge. Sustainability 2020, 12, 5913. [CrossRef]

158. Adedoja, O.S.; Hamam, Y.; Khalaf, B.; Sadiku, R. A state-of-the-art review of an optimal sensor placement for contaminant warning system in a water distribution network. Urban Water J. 2018, 15, 985-1000. [CrossRef]

159. Ostfeld, A.; Uber, J.G.; Salomons, E.; Berry, J.W.; Hart, W.E.; Phillips, C.A.; di Pierro, F. The battle of the water sensor networks (BWSN): A design challenge for engineers and algorithms. J. Water Resour. Plan. Manag. 2008, 134, 556-568. [CrossRef]

160. Giudicianni, C.; Herrera, M.; Di Nardo, A.; Greco, R.; Creaco, E.; Scala, A. topological placement of quality sensors in water-distribution networks without the recourse to hydraulic modelling. J. Water Resour. Plan. Manag. 2020, 146, 04020030. [CrossRef]

161. Lee, C.W.; Yoo, D.G. Decision of water quality measurement locations for the identification of water quality problems under emergency link pipe operation. Appl. Sci. 2020, 10, 2707. [CrossRef]

162. Bazargan-Lari, M.R.; Kerachian, R.; Afshar, H.; Bashi-Azghadi, S.N. Developing an optimal valve closing rule curve for real-time pressure control in pipes. J. Mech. Sci. Technol. 2013, 27, 215-225. [CrossRef]

163. Galelli, S.; Goedbloed, A.; Schwanenberg, D.; van Overloop, P.J. Optimal real-time operation of multipurpose urban reservoirs: Case study in Singapore. J. Water Resour. Plan. Manag. 2012, 140, 511-523. [CrossRef]

164. Creaco, E.; Franchini, M. A new algorithm for real-time pressure control in water distribution networks. Water Sci. Technol. Water Supply 2013, 13, 875-882. [CrossRef]

165. Wright, R.; Stoianov, I.; Parpas, P.; Henderson, K.; King, J. Adaptive water distribution networks with dynamically reconfigurable topology. J. Hydroinform. 2014, 16, 1280-1301. [CrossRef]

Publisher's Note: MDPI stays neutral with regard to jurisdictional claims in published maps and institutional affiliations.

(C) 2020 by the authors. Licensee MDPI, Basel, Switzerland. This article is an open access article distributed under the terms and conditions of the Creative Commons Attribution (CC BY) license (http://creativecommons.org/licenses/by/4.0/). 